\title{
Analysis of the daylight performance of a glazing system with Parallel Slat Transparent Insulation Material (PS-TIM)
}

\author{
Yanyi Sun, Yupeng Wu* and Robin Wilson \\ Department of Architecture and Built Environment, Faculty of Engineering, The University of \\ Nottingham, University Park, Nottingham, NG7 2RD, UK \\ *Corresponding author: Tel: +44 (0) 11574 84011; emails: Yupeng.Wu@nottingham.ac.uk, \\ Jackwuyp@googlemail.com
}

Abstract:

Daylight plays an important role in the energy efficiency and indoor environmental quality of an office building. An innovative façade system where parallel transparent/translucent plastic slats are sandwiched between glass panes to form a Parallel Slat Transparent Insulation Material (PS-TIM) is proposed as a strategy to effectively increase the thermal resistance of window systems, while providing better daylight performance. In this paper, the optical performance (as defined by Bidirectional Scattering Distribution Function) of a double glazed window containing PS-TIM systems with different slat pitches (the distance between neighbouring slats), slat tilt angles, as well as the slat materials (transparent and translucent) was obtained using a ray-tracing technique. Then, the annual daylight performance of a typical office building with various PS-TIM applied under different climatic conditions and at different orientations was investigated using RADIANCE. The simulation results show that PS-TIMs with translucent slats offer better daylight performance than conventional double glazing: it can increase the percentage of annual working hours under daylight, where the illuminance lies in the useful range of up to $79 \%$. It also achieves a homogenous distribution of daylight within the internal working space and effectively reduces the possibility of glare. When applying PSTIM at higher site latitude, smaller slat pitches are required to maximise useful daylight. Optimised PS-TIM geometry is also affected by local prevailing sky conditions.

Keywords: Parallel Slat Transparent Insulation Material (PS-TIM); RADIANCE; daylight performance. 


\section{1. Introduction}

The quantity, quality and distribution of daylight that passes through a window system and illuminates a space, plays an important role in energy efficiency and achieving a comfortable indoor environment. It influences lighting, heating and cooling energy consumption, as well as the thermal and visual comfort perceived by a building's occupants [1]. Additionally, the comfort level provided by daylighting has also been proven to affect human health, mood, activity and work efficiency [2]. Thus, a good design of window system becomes increasingly important. This requires that significant attention is given to designing an effective system that offers a balanced strategy incorporating advances in both thermal and optical thinking, as well as effective use of building prediction methods to quantify performance when applying these novel systems to buildings.

The use of Transparent Insulation Materials (TIM) sandwiched between the panes of a double-glazed window unit is proposed as a strategy for, offering the potential to increase the thermal resistance of a double glazed window, to maintain access to solar light and heat, and to provide a comfortable pattern of daylight distribution. Parallel slat TIM (PS-TIM), as illustrated in Figure 1, divides the air cavity between two glazing panes into small horizontal, linear cells. The slats themselves provide additional viscous resistance to the onset of free convection and in addition interfere with the thermal radiation transferred from one pane of the double glazed unit to the other. As demonstrated by Sun et al. [3], the employment of PS-TIM can reduce the heat transfer coefficient of a double-glazed unit, and in so doing, improve the thermal behaviour of buildings they are employed in. The employment of PS-TIM does, however, reduce the amount of daylight transmitted through the window system as well as modify the daylight distribution within the space it serves. The improved thermal insulation offered by integrating PS-TIM into windows and its effect 
1 on indoor illuminance level can ultimately affect the overall energy efficiency of the

2 building. The daylight aspect of PS-TIM behaviour serves as the focus of this paper.

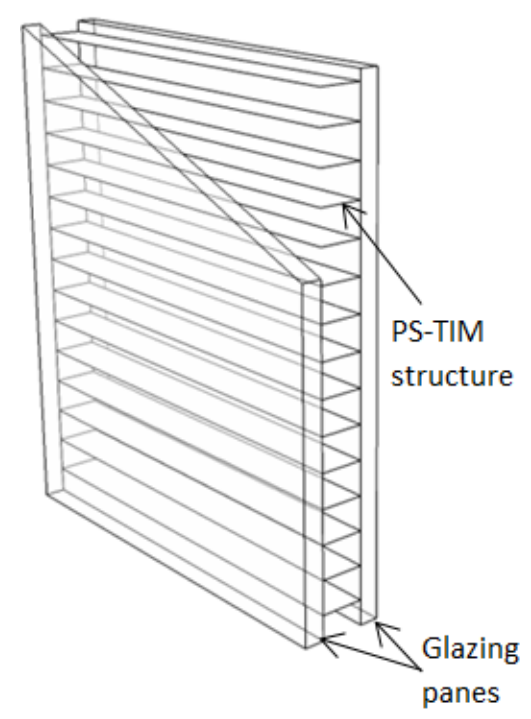

Figure 1: PS-TIM in a double glazed unit

In seeking to evaluate the quantity, quality and distribution of daylight accurately, traditional approaches, which are mainly based on the use of rule of thumb or simplified calculation methods (e.g. daylight factor (DF)) are increasingly deemed inadequate [2]. In a move to improve the objectivity and accuracy when evaluating daylight strategies, a number of new and refined metrics, such as useful daylight illuminance (UDI), daylight glare probability $(D G P)$ etc., have been proposed [4-6] and are becoming increasingly common in the literature [7-11]. These sophisticated metrics are evaluated using dynamic simulation tools (e.g. RADIANCE [12-15]) in conjunction with a Bidirectional Scattering Distribution Function (BSDF) to represent the optical performance of complex window systems [12, 16-18].

This paper provides a comprehensive picture of daylight performance when applying PS-TIMs to window system through the use of dynamic metrics. RADIANCE has been used to determine the dynamic daylighting performance of a notional double glazed window system with and without PS-TIM installed in a typical office, using a "Three-phase method", commonly employed in the daylight simulation of complex fenestration systems. 
1 In the simulation, a cellular office room with various window systems is modelled, and the

2 illuminance distribution calculated for 1 hour time-step over the course of a year. The

3 predicted illuminances during working hours were analysed using advanced metrics (e.g.

$4 U D I, D G P$ and $U R$ ). The influence of slat pitch (the distance between neighbouring slats),

5 slat tilt angle, as well as the optical performance of the slat material itself for the PS-TIMs

6 are also investigated to understand their effects on the overall daylight performance. The

7 chosen PS-TIMs have also been investigated under different climate conditions and

8 different building orientations to provide an indication of how site-specific variables

9 influence performance.

10 It is worth noting that although PS-TIM has the potential to offer improved

11 performance of daylight distribution, the designer would have to consider the extent to 12 which they interrupt view out of and in to building. This study looks only at daylight 13 behaviour and does not consider the effect that PS-TIM has on view. 


\section{2. Daylight performance assessment metrics}

The use of "rule of thumb" methods [19], such as window area to floor area ratios

3 to verify the daylighting sufficiency, or calculation of daylight factor (DF), which is

4 defined as the ratio between indoor to outdoor illuminance and can be used to estimate the

5 adequacy of daylight provision, are wide spread throughout many countries. Although,

6 these methods are frequently formalised within national standards and form part of the

7 standard set of tools used by designers [2], their accuracy can be limited as they frequently

8 fail to take into account the specificity of building site (e.g. orientation, surrounding

9 conditions etc.), local climate and, related to this, the effect of direct sunlight [20]. When

10 working with complex fenestration systems, which cause redirection and scattering of

11 daylight, availability of more accurate methods and more advanced metrics becomes even

12 more pressing. Key static metrics as well as dynamic metrics that are based on annual

13 climate data, encompassing both daylight availability and user comfort levels in a room, are 14 compared and summarised in Tables 1 and 2. 


\begin{tabular}{|c|c|c|c|c|c|c|c|}
\hline & $\begin{array}{l}\text { Static } \\
\text { metrics }\end{array}$ & $\begin{array}{l}\text { Climate- } \\
\text { based } \\
\text { metrics }\end{array}$ & $\begin{array}{c}\text { Daylight } \\
\text { availability }\end{array}$ & $\begin{array}{l}\text { Visual } \\
\text { comfort }\end{array}$ & $\begin{array}{l}\text { Included in } \\
\text { standards or green } \\
\text { buildings } \\
\text { verification tools? }\end{array}$ & Description & Thresholds \\
\hline $\begin{array}{l}\text { Daylight factor } \\
(D F)\end{array}$ & $\checkmark$ & & $\checkmark$ & & $\begin{array}{c}\text { Yes, most of the } \\
\text { national daylighting } \\
\text { standards, e.g. } \\
\text { American IESNA } \\
\text { standards [21] and } \\
\text { Chinese standards } \\
\text { [22] }\end{array}$ & $\begin{array}{l}D F \text { is a ratio of interior } \\
\text { illuminance at a point within a } \\
\text { building to the exterior horizontal } \\
\text { illuminance under an } \\
\text { unobstructed CIE overcast sky } \\
\text { [23] }\end{array}$ & $\begin{array}{l}\text { At least } 2 \% \text { for office } \\
\text { spaces in most of standards }\end{array}$ \\
\hline $\begin{array}{l}\text { Clear sky studies } \\
\text { on solstice and } \\
\text { equinox days }\end{array}$ & $\checkmark$ & & $\checkmark$ & $\checkmark$ & $\begin{array}{l}\text { Yes, e.g. LEED } \\
\text { rating system [24] }\end{array}$ & $\begin{array}{l}\text { Daylighting in a space with a } \\
\text { fenestration system under clear } \\
\text { sky conditions at } 9 \text { am, noon and } \\
3 \text { pm on solstice and equinox days, } \\
\text { expressed in illuminance or } \\
\text { luminance [20] }\end{array}$ & N/A \\
\hline $\begin{array}{l}\text { Useful daylight } \\
\text { illuminance } \\
\text { (UDI) }\end{array}$ & & $\checkmark$ & $\checkmark$ & & No & $\begin{array}{l}\text { By using lower and upper } \\
\text { thresholds, UDI divides the } \\
\text { illuminance level of hours in a } \\
\text { year into three bins [6] }\end{array}$ & $\begin{array}{l}\text { Undersupply bin: < } 100 \text { lux } \\
\text { Useful bin: } 100 \sim 2000 \text { lux } \\
\text { Oversupply bin: > } 2000 \text { lux }\end{array}$ \\
\hline $\begin{array}{l}\text { Illuminance } \\
\text { uniformity ratio } \\
(U R)\end{array}$ & & $\checkmark$ & & $\checkmark$ & $\begin{array}{l}\text { Yes, e.g. BREEAM } \\
\text { rating system [25] }\end{array}$ & $\begin{array}{l}\text { Uniformity is the ratio between } \\
\text { maximum and minimum } \\
\text { illuminance inside a space [26] }\end{array}$ & $\begin{array}{l}1: 5 \text { in CIBSE [27] } \\
1: 2.5 \text { in BREEAM [25] }\end{array}$ \\
\hline $\begin{array}{l}\text { Simplified } \\
\text { daylight glare } \\
\text { probability } \\
(D G P \text { s })\end{array}$ & & $\checkmark$ & & $\checkmark$ & No & $\begin{array}{l}\text { A simplified annual method to } \\
\text { evaluate daylight glare based on } \\
\text { vertical illuminance }\left(E_{v}\right)[4,28] \text { : } \\
\qquad D G P s=6.22 \times 10^{-5} E_{v}+0.184\end{array}$ & $\begin{array}{ll}\text { Imperceptible: } & \leq 0.35 \\
\text { Perceptible: } & 0.35 \sim 0.4 \\
\text { Disturbing: } & 0.4 \sim 0.45 \\
\text { Intolerable: } & \geq 0.45\end{array}$ \\
\hline
\end{tabular}




\begin{tabular}{|c|c|c|}
\hline & Advantages & Disadvantages \\
\hline $\begin{array}{l}\text { Daylight factor } \\
(D F)\end{array}$ & $\begin{array}{ll}\text { - } & \text { Simple to calculate } \\
\text { - } & \text { Widely used in daylight standards }\end{array}$ & $\begin{array}{l}\text { - Building sites, climate, time in the day and variable sky } \\
\text { conditions [20] are not considered } \\
\text { - } \quad \text { Direct solar ingress is not considered, only diffuse } \\
\text { - Standards that do not recommend maximum } D F s \text { can lead } \\
\text { to oversupply of daylight, risk of thermal discomfort and } \\
\text { possibility of glare }\end{array}$ \\
\hline $\begin{array}{l}\text { Clear sky studies } \\
\text { on solstice and } \\
\text { equinox days }\end{array}$ & $\begin{array}{l}\text { An intuitive expression of the daylight distribution (i.e. } \\
\text { illuminance or luminance) under different solar incident } \\
\text { angles }\end{array}$ & $\begin{array}{l}\text { - } \quad \text { Specific climate data are not considered } \\
\text { - } \quad \text { Requires a large number of individual simulations and a } \\
\text { review of multiple figures }\end{array}$ \\
\hline $\begin{array}{l}\text { Useful daylight } \\
\text { illuminance } \\
(\text { UDI })\end{array}$ & $\begin{array}{l}\text { Takes into account the hours of actual operation and real } \\
\text { weather conditions at the site } \\
\text { - } \quad \text { Uses an upper threshold to avoid oversupply conditions } \\
\text { - } \quad \text { Good for comparing the performance of different design } \\
\text { variations }\end{array}$ & $\begin{array}{l}\text { - } \quad \text { Requires specialized experience for simulation } \\
\text { Time-consuming calculation since it is necessary to } \\
\text { determine illuminance for every daylight hour over the } \\
\text { course of a year on each study point }\end{array}$ \\
\hline $\begin{array}{l}\text { Illuminance } \\
\text { uniformity ratio } \\
(U R)\end{array}$ & $\begin{array}{l}\text { - Gives an intuitive impression of how uniformly daylight is } \\
\text { distributed in a space }\end{array}$ & $\begin{array}{l}\text { - } \\
\text { - Time-consuming calculation since it is necessary to } \\
\text { determine illuminance for every daylight hour over the } \\
\text { course of a year on each study point }\end{array}$ \\
\hline $\begin{array}{l}\text { Simplified } \\
\text { daylight glare } \\
\text { probability } \\
(D G P)\end{array}$ & $\begin{array}{l}\text { Effective method to accumulate the probability of daylight } \\
\text { glare for a view direction for every daylight hour in a year }\end{array}$ & $\begin{array}{l}\text { Invalid for situations where sunlight enters the occupant's } \\
\text { direct field of view } \\
\text { - Computationally intensive calculation }\end{array}$ \\
\hline
\end{tabular}




\section{3. Simulation method}

The generation of daylight performance metrics can be performed using annual

3 hourly simulation results obtained from RADIANCE [29]. RAIDANCE is a software tool

4 based on a backward ray-tracing algorithm, which means that the rays are emitted from the

5 point of interest and traced backwards until they either hit a light source or another object [30].

6 The accuracy of this research-grade simulation tool has been validated by several studies [12-

7 15].

For a dynamic daylight simulation of a space, hourly based annual climate data, which includes direct sunlight and diffuse skylight, are required for the daylight performance prediction. For a space illuminated via a complex fenestration system, such as PS-TIM, the multiple inter-reflections that occur within the system become a further challenge for dynamic annual simulation. Swapping these complex interactions with a pre-calculated transmission matrix, $(T)$, which characterizes flux output as a function of input for a particular configuration of light source and receiver, provides a simple but effective description of complex fenestration system in RADIANCE [12]. In addition, a daylight matrix, $(D)$, and a view matrix, $(V)$, that describe the external and internal conditions respectively, may also be calculated using a modified daylight coefficient method in advance of annual simulation [16]. Flux transfer represented by these three matrices forms a "Three-phase method", where the matrices are used in a multiple inner time-step loop with an assigned value for the sky condition (sky vector $(s)$ or sky matrix $(S)$ ). This is proposed as a means of effectively and accurately performing annual daylight simulations of systems where complex fenestration systems are applied $[12,16,31]$. The results, which can be illuminance or luminance at any point of interest for a single time step $(i)$ or for a time series (I), are computed using the 24 following equations: 
2 where the sky vector $(s)$ is generated by dividing the whole sky into discrete patches, with

3 each patch being assigned an average radiance value for a given time and sky condition, while

4 the sky matrix $(S)$ is a time series of sky vectors. An annual sky matrix is generated from 5 hourly input weather data for the 8760 hours in a year.

In this research, the 'Three-phase method' was used to conduct the dynamic annual daylight simulation of PS-TIM window systems in an office. The daylight matrix and view matrix were obtained based on the model's orientation, surrounding environment, geometry and surface properties of the indoor space (details can be found in section 3.3) using an embedded command in RADIANCE. Sky matrices were obtained from IWEC (International Weather for Energy Calculation) weather data for five cities with different latitudes and climates (details can be found in section 3.2). The transmission matrix for the window systems with PS-TIM was expressed using Bidirectional Scattering Distribution Functions $(B S D F s)$ (details can be found in section 3.1).

\subsection{BSDF for a window system with PS-TIM}

A $B S D F$ file defines coefficients to allocate light from each exterior direction to each interior direction. In so doing, the angularly resolved transmissions and reflections for a complex window system are included in the annual calculation process. The BSDF based on Klems angle basis is a primary format for RADIANCE. As shown in Figure 2, it comprises $145 \times 145$ matrices for fenestration systems, which can account for the transformations that occur to both solar and optical spectra. Each matrix describes reflectance or transmittance distribution in the outgoing hemisphere for each incident angle of the incoming hemisphere. 

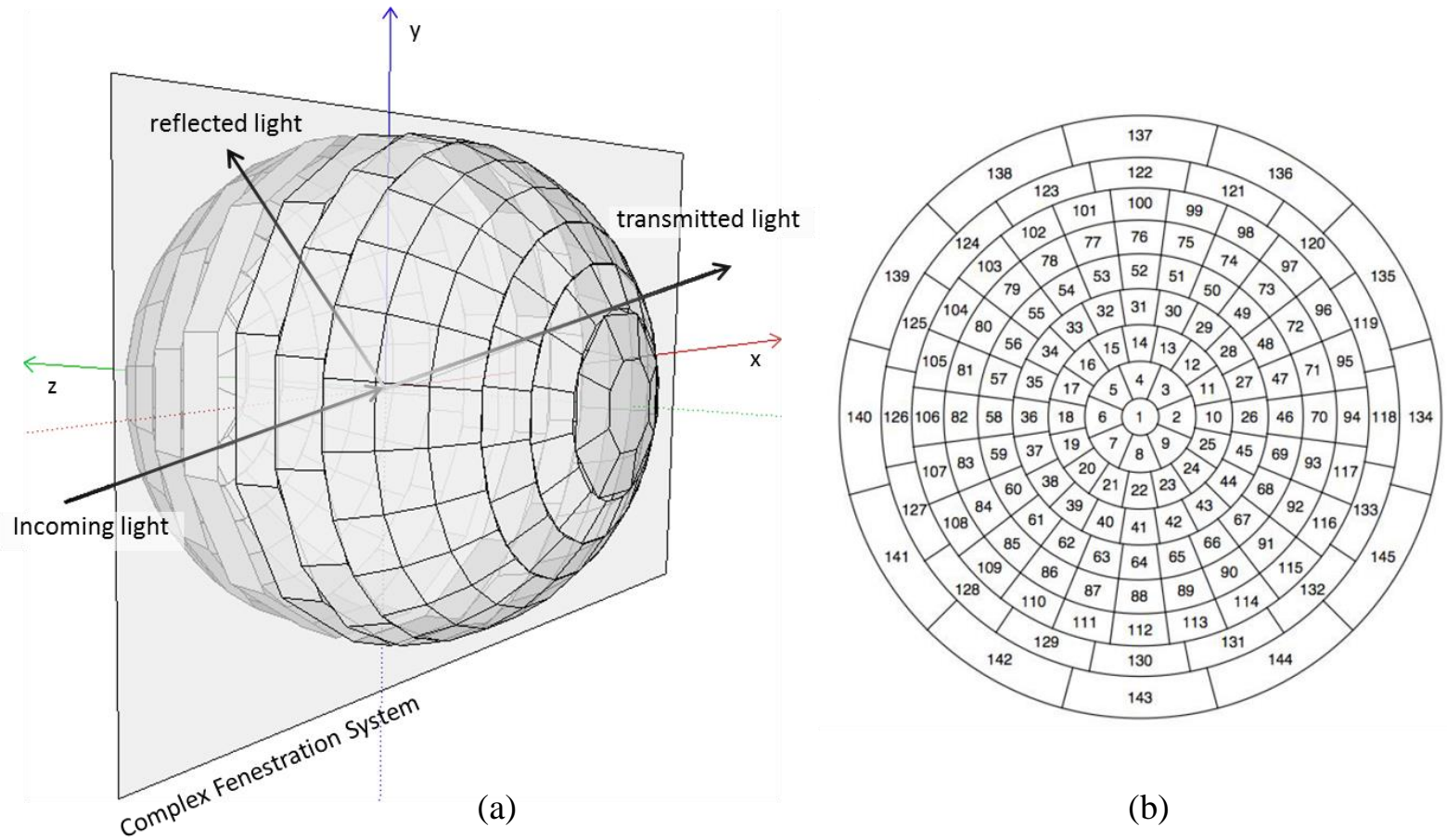

(b)

Figure 2: (a) schematic diagram of BSDF and (b) Klems 145-patch hemispherical basis with numbered subdivisions

The BSDF can be obtained by two methods: measurement using goniophotometric equipment [32-34] or calculation using validated ray-tracing methods [33-35]. A ray-tracing program genBSDF in RADIANCE [29], which has been validated by McNeil et al. [35], was used in this research to calculate $B S D F$ of different interstitial PS-TIM structures based on their geometry and material properties.

The BSDF data was calculated by RADIANCE for PS-TIM systems with 4 slat pitches $(15 \mathrm{~mm} 10 \mathrm{~mm} 7.5 \mathrm{~mm}$ and $5 \mathrm{~mm})$, at 7 different slat orientation angles $\left(0^{\circ}, 30^{\circ}, 45^{\circ}\right.$, $60^{\circ},-30^{\circ},-45^{\circ}$ and $-60^{\circ}$ ) and 2 different slat materials (transparent and Lambertian diffuse translucent with 50\% transmission). Examples of the investigated PS-TIM with different slat pitches are shown in Figure 3 (a), PS-TIM with different tilt angles are shown in Figure 3 (b) and PS-TIM with different slat materials are shown in Figure 3 (c). 


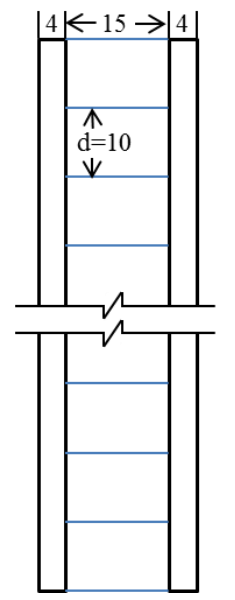

10 mm_0 ${ }^{\circ}$

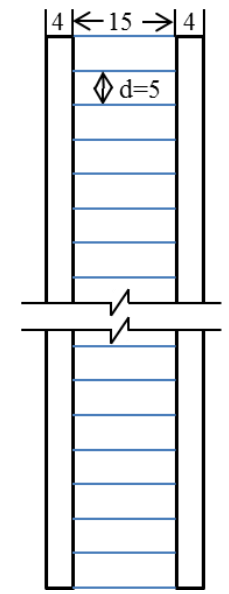

(a)

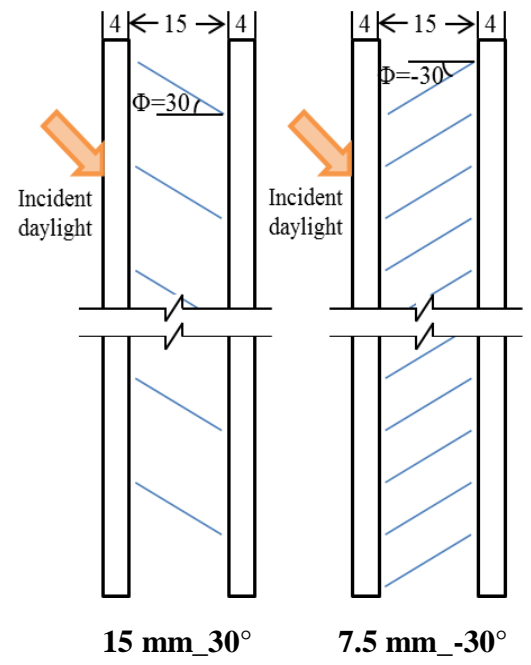

(b)

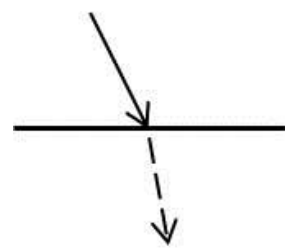

Transparent

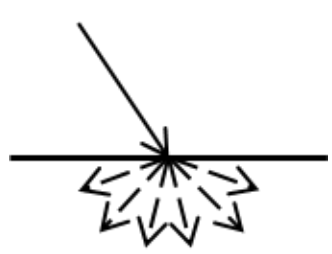

Lambertian translucent

(c)

1 Figure 3: Schematic diagram of variables: (a) slat pitch (d mm); (b) tilt angle $\left(\Phi^{\circ}\right)$ and (c) slat material

Table 3: Latitude, longitude and annual average solar irradiance for five case study cities

\subsection{Weather data}

To investigate the performance of the proposed PS-TIMs under different geographical and weather conditions, five cities: Stockholm; London; Beijing; Hong Kong and Singapore were selected. The latitude, longitude and solar radiation conditions for these cities are shown in Table 3. The simulations were run at 1-hour time-steps for an entire year using IWEC weather file for the site. The diurnal direct and diffuse solar radiation of these five cities can

\begin{tabular}{lccccc}
\hline & \multirow{2}{*}{ Latitude } & Longitude & \multicolumn{3}{c}{ Noon solar altitude } \\
\cline { 4 - 6 } & & & summer solstice & equinox & winter solstice \\
\hline Stockholm & $59.3^{\circ} \mathrm{N}$ & $18^{\circ} \mathrm{E}$ & $53.1^{\circ}$ & $28.7^{\circ}$ & $6.7^{\circ}$ \\
London & $51.5^{\circ} \mathrm{N}$ & $0^{\circ} \mathrm{W}$ & $62.1^{\circ}$ & $37.6^{\circ}$ & $15.2^{\circ}$ \\
Beijing & $39.9^{\circ} \mathrm{N}$ & $116^{\circ} \mathrm{E}$ & $70.7^{\circ}$ & $48.6^{\circ}$ & $25.7^{\circ}$ \\
Hong Kong & $22.3^{\circ} \mathrm{N}$ & $114.2^{\circ} \mathrm{E}$ & $77.2^{\circ}$ & $62.2^{\circ}$ & $42.5^{\circ}$ \\
Singapore & $1.3^{\circ} \mathrm{N}$ & $103.8^{\circ} \mathrm{E}$ & $67.8^{\circ}$ & $88.6^{\circ}$ & $65.2^{\circ}$ \\
\hline
\end{tabular}

\subsection{Model geometry and material properties}

A side lit cellular office with dimensions $2.9 \mathrm{~m}($ width $) \times 4.4 \mathrm{~m}($ depth $) \times 3.3 \mathrm{~m}$

12 (height), which is based on a real room in the Energy Technologies Building in the University 13 of Nottingham, UK, was chosen for the simulation. The office surfaces were treated as 
1 perfectly diffuse with typical visible reflectances of $30 \%$ (floor), $80 \%$ (walls) and $80 \%$

2 (ceiling). In order to clearly describe the geometry of the room, the four walls are represented

3 by $\mathrm{A}, \mathrm{B}, \mathrm{C}$ and $\mathrm{D}$ as illustrated in Figure 4 . A window with dimensions $1.4 \mathrm{~m}$ (height $) \times 2.9$

$4 \mathrm{~m}$ (width) is located in wall A with a sill height of $1.1 \mathrm{~m}$ above the floor. Four window

5 orientations: South, East, West and North are considered in the studies. The original double

6 glazed window has a visible light transmission of $78 \%$. The furniture inside the room was

7 modelled according to the layout of the prototype office. It was assumed there were no

8 surrounding buildings, vegetation or other obstructions outside the office. An exterior ground

9 with RGB reflectance of $(0.4,0.4$ and 0.1$)$ [29] was used to represent a grass green colour in

10 the external environment. The enclosing surfaces of the room, all the furniture and exterior

11 ground were built up directly in RADIANCE.

A $9 \times 5$ grid comprising 45 points at $0.5 \mathrm{~m}$ centres was used to estimate the illuminance distribution on a working plane positioned at a height of $0.75 \mathrm{~m}$ above floor level as illustrated in Figure 4. The grid was located centrally on plan, $0.2 \mathrm{~m}$ away from wall $\mathrm{A}$ and $\mathrm{C}$ and $0.45 \mathrm{~m}$ away from wall $\mathrm{B}$ and $\mathrm{D}$. The room was assumed to be used as a private office for two people, with one positioned near the window and the second at the back of the room.

17 As glare caused by daylight is less likely to be an issue at the back of the room, the glare

18 evaluation was based on a view point representing the occupant near the window. This was located at a distance of $1.2 \mathrm{~m}$ from the window and at a height of $1.2 \mathrm{~m}$ above the floor on the centre axis of the room; facing wall B or D. 


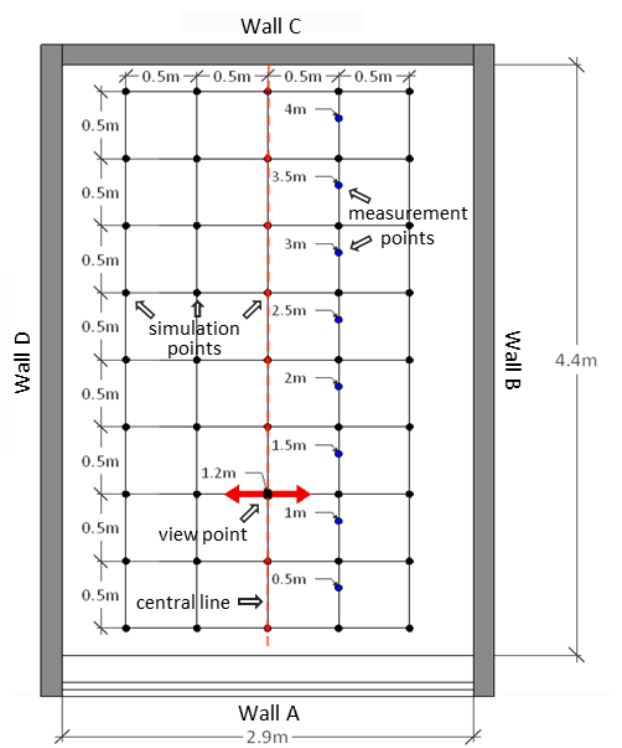

(a)

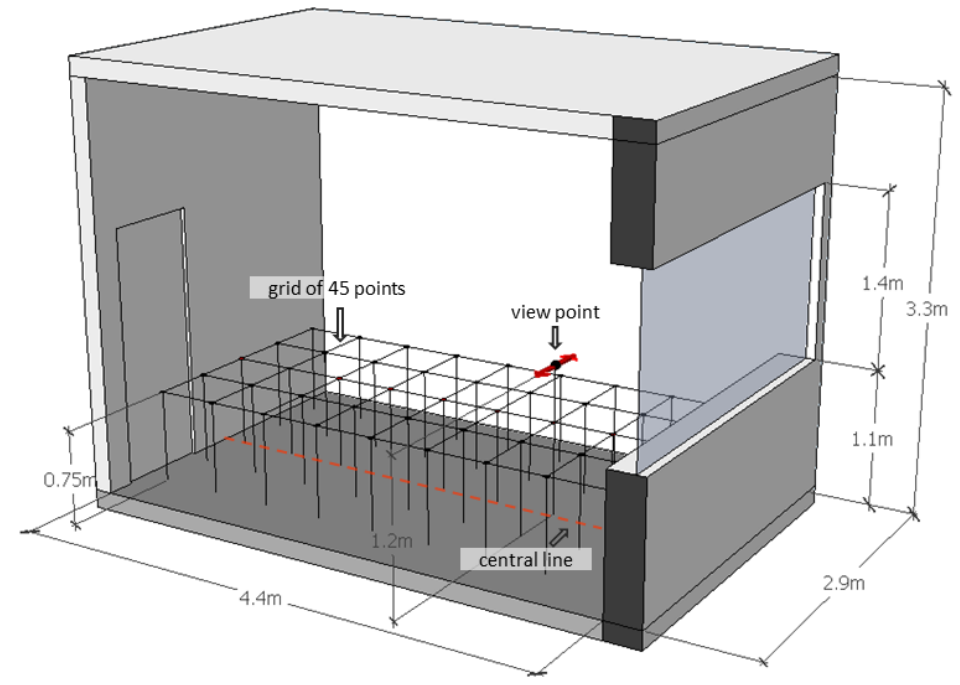

(b)

2 Figure 4: Selected points for evaluating illuminance distribution in the office space (a) Plan view and (b) sectional view

\section{4} this study, the following rendering parameters for RADIANCE were used:

\subsection{Simulation conditions and rendering parameters}

The room is schedule assumed occupancy schedule between 8:00 and 17:00. Within

Table 4: RADIANCE simulation parameters

\begin{tabular}{cccccc}
\hline $\begin{array}{c}\text { Ambient } \\
\text { bounces } \\
(-\mathbf{- a b})\end{array}$ & $\begin{array}{c}\text { Ambient } \\
\text { divisions } \\
\mathbf{( - a d )}\end{array}$ & $\begin{array}{c}\text { Ambient } \\
\text { supersamples } \\
(\mathbf{- a s})\end{array}$ & $\begin{array}{c}\text { Ambient } \\
\text { resolution } \\
(\mathbf{( - a r )}\end{array}$ & $\begin{array}{c}\text { Ambient } \\
\text { accuracy } \\
\mathbf{( - a a )}\end{array}$ & $\begin{array}{c}\text { Direct } \\
\text { sampling } \\
(\mathbf{- d s})\end{array}$ \\
\hline 12 & 50000 & 512 & 256 & 0.13 & 0.2 \\
\hline
\end{tabular}

According to investigations undertaken by Wienold and McNeil [4, 31], these settings

9 seem to deliver reliable values for the given scenes.

\subsection{Model validation}

The accuracy of the RADIANCE algorithm, daylight coefficient method and Perez sky model have been discreetly validated under over 10,000 sky conditions including overcast skies, clear skies and partly cloudy skies by Reinhart [14,36] and Mardaljevic [37, 38]. They used the data from a sky scanner to describe the luminance distribution of the celestial hemisphere including the sun in their simulation model, and then compared the simulated 
1 results of indoor illuminance level under each sky condition with the measured results under

2 the same condition. The results indicated a high level of reliability in the use of RADIANCE

3 to predict the annual indoor illuminance distribution in a space based on the building

4 geometry, optical properties of the material surfaces and direct and diffuse irradiances. In this

5 research, to provide confidence of accurately using RADIANCE for PS-TIM prediction, the

6 illuminances for the prototype room were measured and compared with illuminances from

7 simulation under the same conditions. The illuminance measurement method was a simplified

8 version of the validated method for illuminance measurement developed by Reinhart [14, 36]

9 and Mardaljevic [37, 38]. The measurements were conducted on two overcast days in October

10 2015. As the sky conditions were totally overcast and there was no direct irradiance, the

11 luminance distribution of the celestial hemisphere was assumed to be uniform in the

12 simulation. The external non-obscured horizontal illuminance and indoor illuminances at the

13 selected 8 measurement points (along the centre line of the room between the window and the

14 end wall) were measured using calibrated chromameters, CL-200A (with an accuracy of $\pm 2 \%$

15 or \pm 1 the smallest digit of the displayed value). Comparison was made between the simulated

16 indoor illuminance and the measured illuminance on the working plane (shown in Figure 4).

17 The simulation assumed a typical double glazing (window without TIM) under two external

18 illuminance levels: one with 10,000 lux and the other with 2,500 lux. In order to avoid the

19 influence of a neighbouring building and vegetation on the measured illuminance, the study

20 was based on an office on the top floor of the building.

21 Figure 5 shows a comparison between measured and simulated values. The results 22 agree reasonably well with the greatest deviation (13.5\%) occurring $0.5 \mathrm{~m}$ away from the 23 window when the external horizontal illuminance was 10000 lux. This is due to the presence 24 of a small window sill and an incompletely rolled up blind near top of the window (see Figure 25 6), which lead to more obstruction of light near the window neither of which was considered 
1 in the simulation. A photo of the prototype office room, which is taken during an overcast day,

2 and a simulated render of the model are shown in Figure 6.

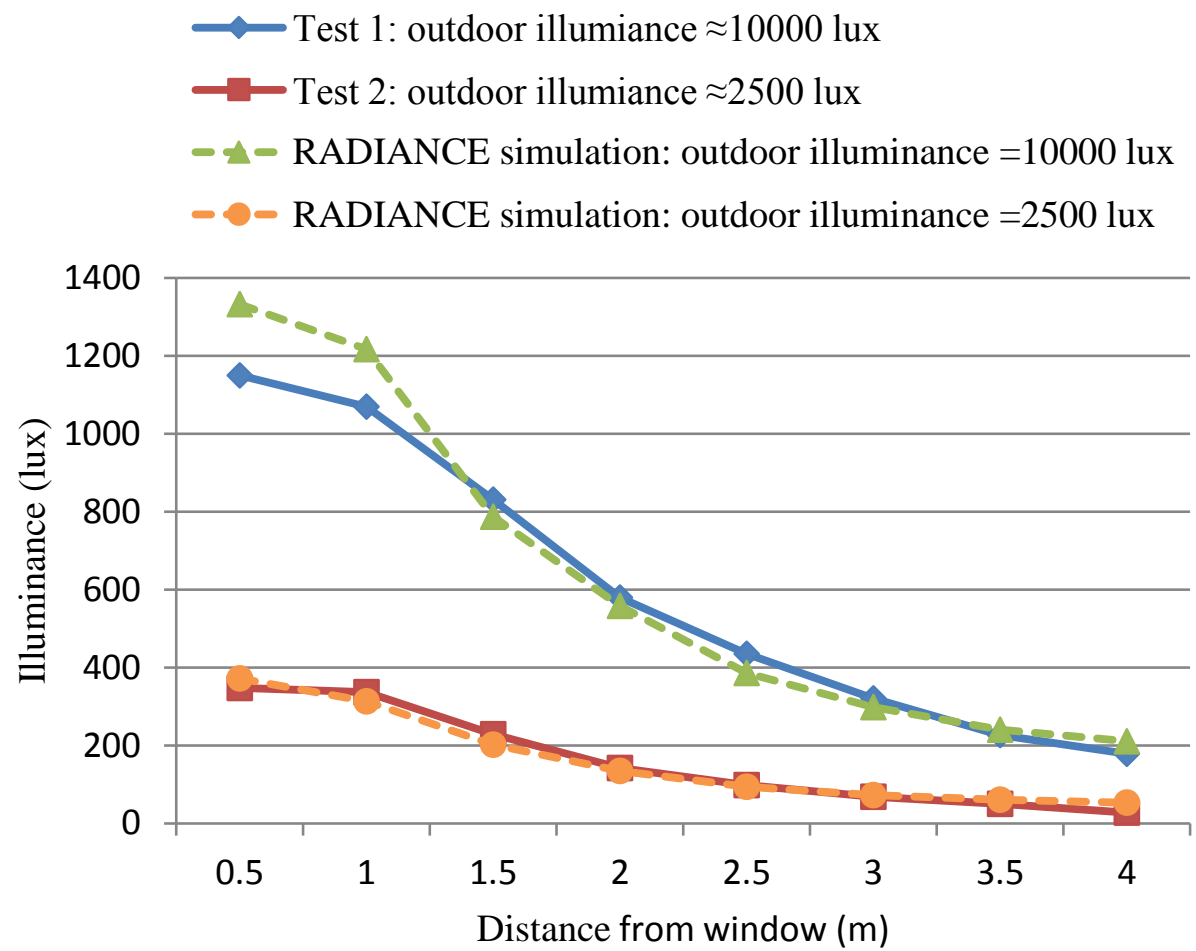

Figure 5: Comparison between measured illuminance and illuminance calculated using Radiance at the selected 8 points in the room

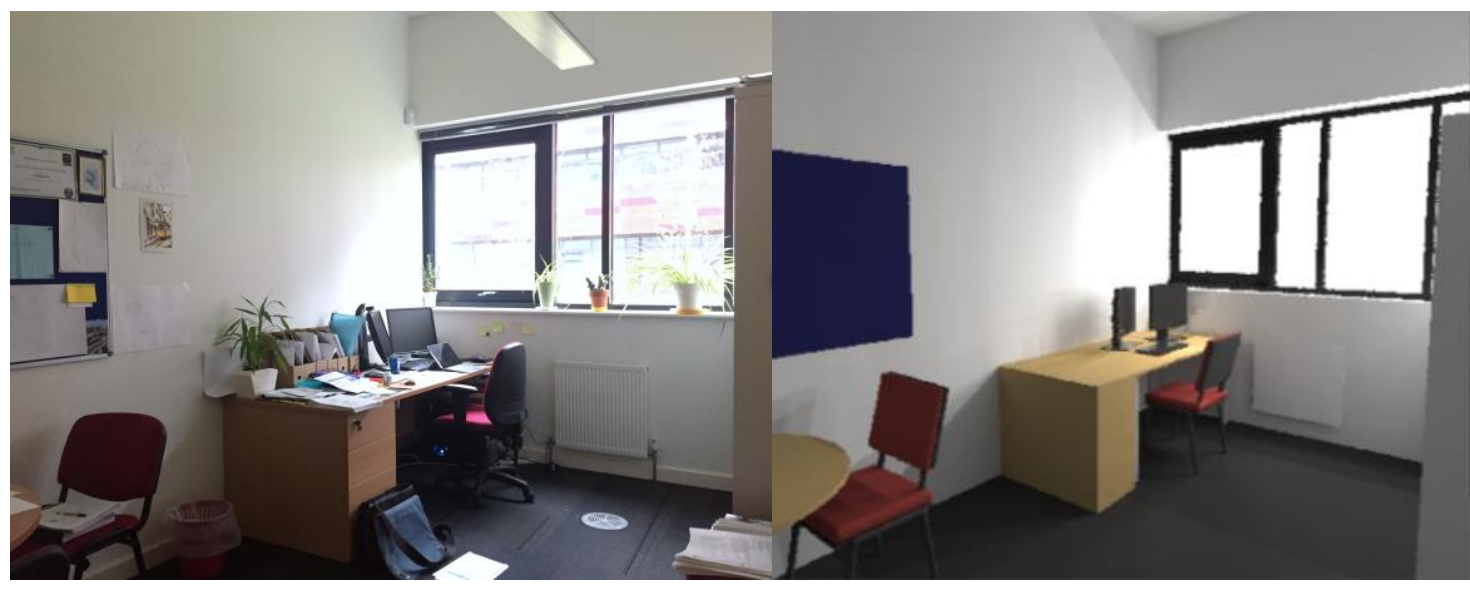

(a)

(b)

Figure 1: (a) Photo of test room and (b) rendered image 


\section{4. Results and discussion of the effect of different PS-TIM on}

indoor daylight performance

The criterion for identifying the optimised PS-TIM configuration was based on attaining a balance between the daylight availability and daylight comfort level.

\section{$5 \quad 4.1$ The effects of slat pitch on daylight performance}

Simulations were undertaken for the PS-TIM with Lambertian diffuse translucent slats placed horizontally between two glazing panes, at various slat pitch of $15 \mathrm{~mm}, 10 \mathrm{~mm}, 7.5$ $\mathrm{mm}$ and $5 \mathrm{~mm}$, (labelled as ' $15 \mathrm{~mm}$ PS-TIM', '10 mm PS-TIM', '7.5 mm PS-TIM' and '5 mm PS-TIM' respectively in preceding discussions). For the results presented in this section, the office is assumed to be located in London with the window facing south. determined by sorting the simulated hourly illuminance at the points of interest into 3 bins:

1) an undersupplied bin (illuminance value < 100 lux);

2) a useful bin (100 lux < illuminance value < 2000 lux);

3) an oversupplied bin (illuminance value > $2000 \mathrm{lux}$ ). splitting it into two ranges:

1) A desired range (500 $2000 \mathrm{lux})$, where a typical office design illuminance is met and is not exceeded to the point where glare is highly likely [20];

2) A sub-desired range $(100 \sim 500$ lux $)$ where there is an increasing likelihood that occupants will resort to supplementary lighting to meet their illumination needs. 
1 1) illuminance in the range of $2000 \sim 3000$ lux, in which range occupants may tolerate the strong daylight;

2) illuminance greater than 3000 lux, in which blinds or shades might be lowered [39].

Predictions were made for the window without PS-TIM and with translucent PS-TIM at 4 different slat pitches. Figure 7 shows the $U D I$ predicted at points along the centre line of the room between the window and the end wall. As illustrated in Figure 7 (a), for the double glazing system, the period when there is an oversupply of daylight $(U D I>3000$ lux $)$ accounts for a high proportion (i.e approximately $45 \%$ of working hours) at locations within $2.2 \mathrm{~m}$ of the window and it gradually reduces to less than $10 \%$, for points further than $3.2 \mathrm{~m}$ from the window. This oversupply of daylight can be reduced to less than $20 \%, 10 \% 5 \%$ and $0 \%$ of working hours by integrating PS-TIM structure with slat pitches of $15 \mathrm{~mm}, 10 \mathrm{~mm} .7 .5 \mathrm{~mm}$ and $5 \mathrm{~mm}$, respectively, as shown in Figure 7 (b), (c), (d) and (e). While the $5 \mathrm{~mm}$ PS-TIM can completely eliminate oversupply of daylight, the percentage of undersupplied daylight hours $\left(U D I_{<100 ~ l u x}\right)$ increases from less than $10 \%$ for conventional double glazing to more than 20\%. The remaining 3 configurations of PS-TIM give rise to undersupplied daylight hours in the range of $10 \%$ to $20 \%$ of working hours.

The average percentage of hours where the UDI is in the most desired range (UDI5002000 lux ) increase from $36 \%$ for conventional double glazing to $46 \%$ and $50 \%$ when applying PS-TIM with $15 \mathrm{~mm}$ slat pitch and $10 \mathrm{~mm}$ slat pitch respectively. The integration of PS-TIM improves the daylighting quality of the room, especially within the region that is close to the window where over illumination is frequently a problem with conventional glazing. Instead, more hours are predicted within the most desired range of UDI (UDI 500-2000 lux), these being relatively evenly distributed throughout the room depth for PS-TIM with slat pitches of $10 \mathrm{~mm}$ or less for around $50 \%$ of working hours. 
Significant improvement over conventional double glazing is achieved by applying

2 PS-TIM with $10 \mathrm{~mm}$ slat pitch and $7.5 \mathrm{~mm}$ slat pitch, which raises the average percentage of

3 useful UDI (UDI $100-500$ lux and $U D I_{500-2000 \text { lux }}$ ) from $47 \%$ to approximately $76 \%$ and $79 \%$,

4 respectively.

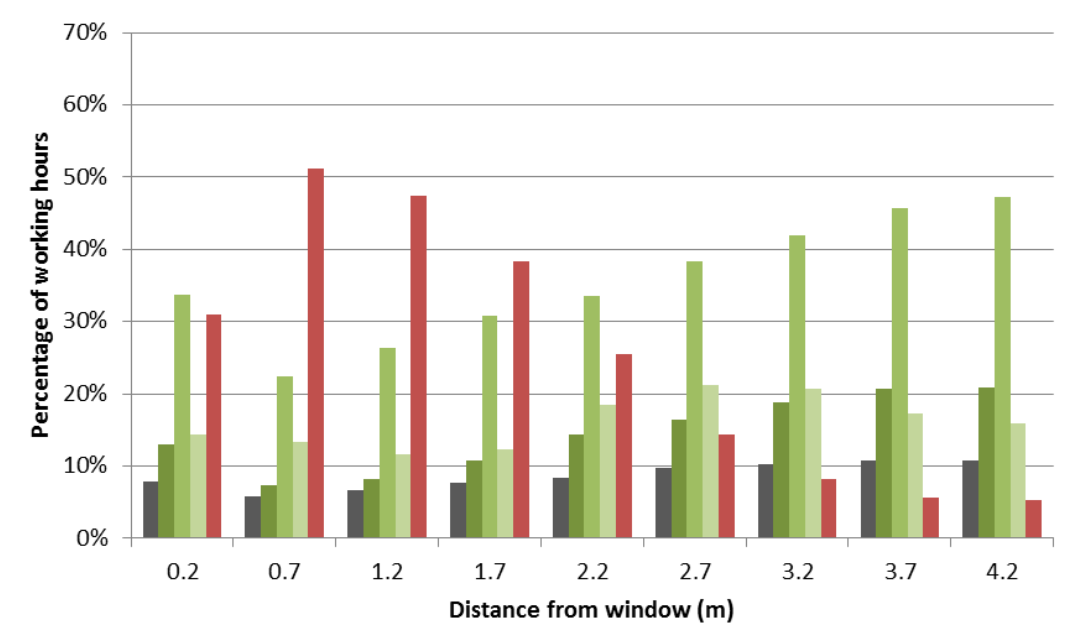

$$
\begin{aligned}
& \hline \text { UDI } \\
& =<100 \text { lux } \\
& =100-500 \text { lux } \\
& \square \text { 500-2000 lux } \\
& =2000-3000 \text { lux } \\
& \square>3000 \text { lux }
\end{aligned}
$$

(a)

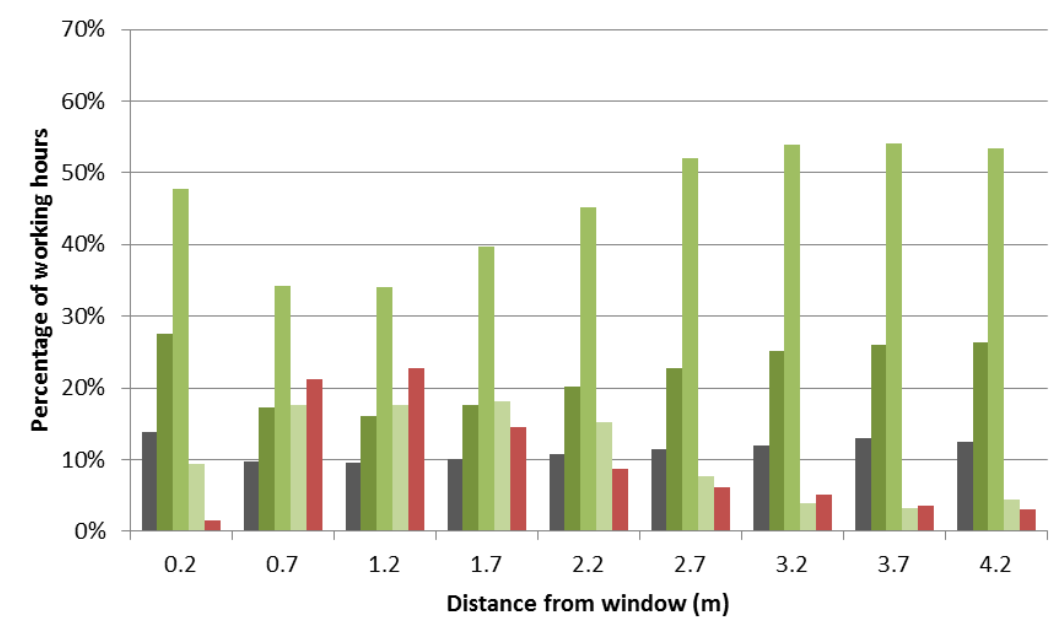

$$
\begin{aligned}
& \text { UDI } \\
& \text { - }<100 \text { lux } \\
& \text {-100-500 lux } \\
& \text { 100-2000 lux } \\
& \text {-2000-3000 lux } \\
& \text { a >3000 lux }
\end{aligned}
$$

(b)

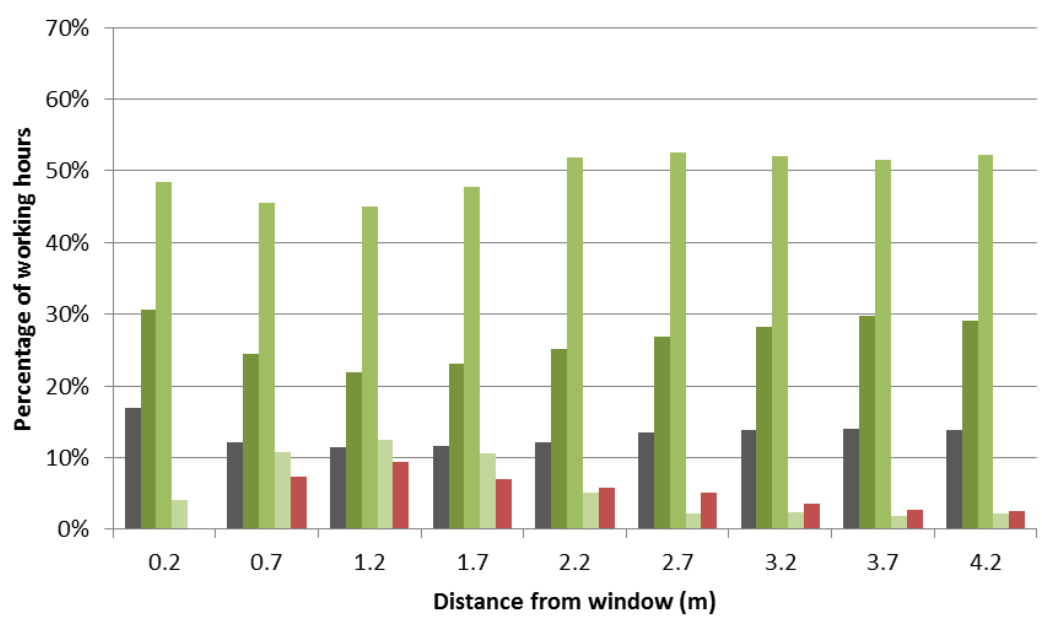

$$
\begin{aligned}
& \text { UDI } \\
& \square<100 \text { lux } \\
& =100-500 \text { lux } \\
& =500-2000 \text { lux } \\
& =2000-3000 \text { lux } \\
& =>3000 \text { lux }
\end{aligned}
$$

(c) 


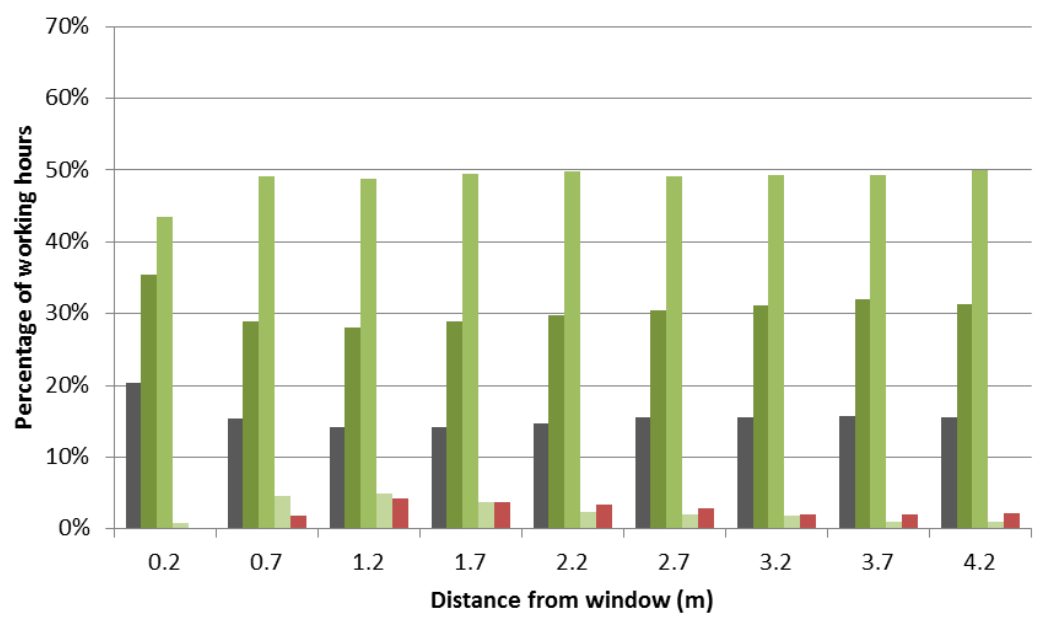

$$
\begin{aligned}
& \text { UDI } \\
& \text { - }<100 \text { lux } \\
& \text {-100-500 lux } \\
& \text { 1. 500-2000 lux } \\
& \text {-2000-3000 lux } \\
& \text { n >3000 lux }
\end{aligned}
$$

(d)

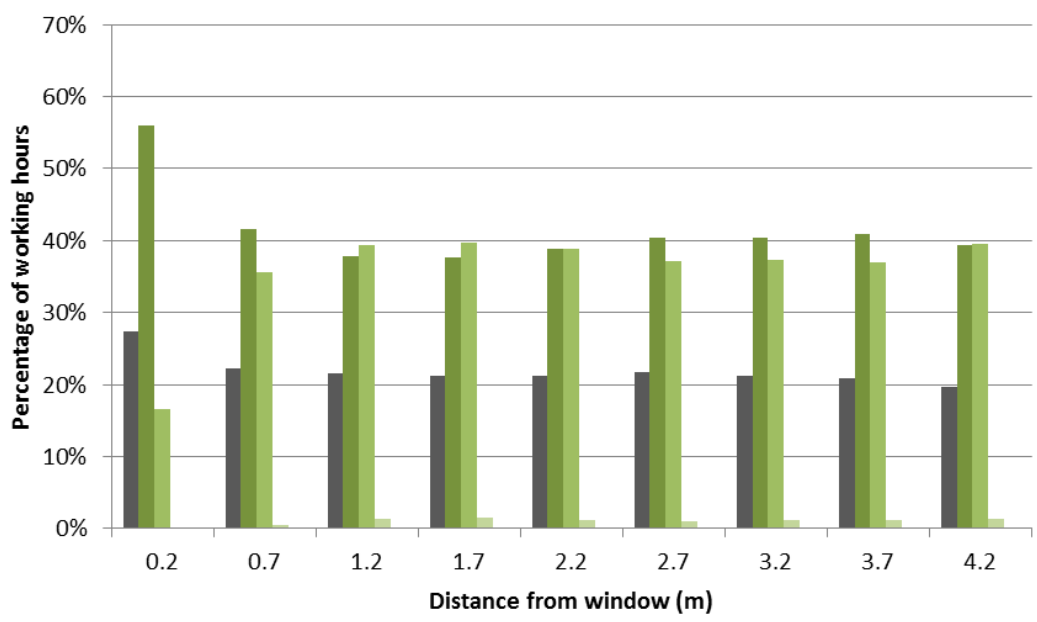

$$
\begin{aligned}
& \hline \text { UDI } \\
& \square<100 \text { lux } \\
& \square 100-500 \text { lux } \\
& \square 500-2000 \text { lux } \\
& \square 2000-3000 \text { lux } \\
& \square>3000 \text { lux }
\end{aligned}
$$

(e)

Figure 7: UDI bins for points located along the central line of an office from window to the end wall for the window system with and without PS-TIM: (a) DG; (b) $15 \mathrm{~mm}$ PS-TIM; (c) $10 \mathrm{~mm}$ PS-TIM; (d) $7.5 \mathrm{~mm}$ PS-TIM and (e) $5 \mathrm{~mm}$ PS-TIM. Simulations are based on a London IWEC weather file. 
The results for additional two metrics, uniformity ratio (UR) (see Table 1 and 2 for

2 more information) and daylight glare probability (DGP) (see Table 1 and 2 for more

3 information), which were used to assess the daylight comfort level are presented in Figure 8.

As with the previous analysis, the data are derived from the London climate data file.

At this latitude, $3 \%$ of the working hours occur before sunrise or after sunset and so have no daylight at all: for $3 \%$ of the time therefore, the $U R$ equals 0 . For conventional double glazing, the daylight transmitted into the room produces extreme contrasts of illumination on the working plane: $42 \%$ of the annual working hours have a $U R$ larger than 1:4.5 (labelled as > 4.5 in Figure 8 (a)) and of working hours $47 \%$ fall into the range between 1:3.5 and 1:4.5 (labelled as 3.5 - 4.5). The application of PS-TIM integrated double glazing improves the predicted illuminance uniformity. UR over 1:2.5 (the sum of the data labelled as 2.5-3.5, 3.54.5 and $>4.5$ ), reduces to $34 \%, 15 \%, 10 \%$ and $4 \%$ of annual working hours for PS-TIM with slat pitches of $15 \mathrm{~mm}, 10 \mathrm{~mm}, 7.5 \mathrm{~mm}$ and $5 \mathrm{~mm}$, respectively.

The daylight glare probability $(D G P)$ is calculated based on a simplified annual simulation method for the assumed occupant position near the window (1.2 $\mathrm{m}$ away from window at $1.2 \mathrm{~m}$ height) [4, 5]. As shown in Figure 8 (b), for the normal double glazed window, the intolerable glare $(D G P \geq 0.45)$, disturbing glare $(0.4<D G P<0.45)$, and perceptible glare $(0.35<D G P<0.4)$ account for $13.9 \%, 6.4 \%$ and $16.6 \%$ of working hours, respectively. When diffuse translucent PS-TIM structures are applied, significant improvement of the percentage of imperceptible glare $(D G P \leq 3.5)$ is achieved. This increases from $63.1 \%$ of working hours for DG to $87.8 \%, 93.4 \%, 96.5 \%$ and $99.2 \%$ with the application of PS-TIM with slat pitches of $15 \mathrm{~mm}, 10 \mathrm{~mm}, 7.5 \mathrm{~mm}$ and $5 \mathrm{~mm}$, respectively. According to the Wienold's criteria [4] for categorising glare conditions in a room, when $7.5 \mathrm{~mm}$ PS-TIM and $5 \mathrm{~mm}$ PS-TIM are applied, the room has a 'Best' classification for over $95 \%$ of office working hours and the glare sensation would be deemed imperceptible. The $10 \mathrm{~mm}$ PS-TIM 
1 offers a 'Good' classification as over $95 \%$ of office working hours the glare is perceptible and

2 the $15 \mathrm{~mm}$ PS-TIM has a 'Reasonable' classification as fewer than 5\% of office working 3 hours have intolerable glare.

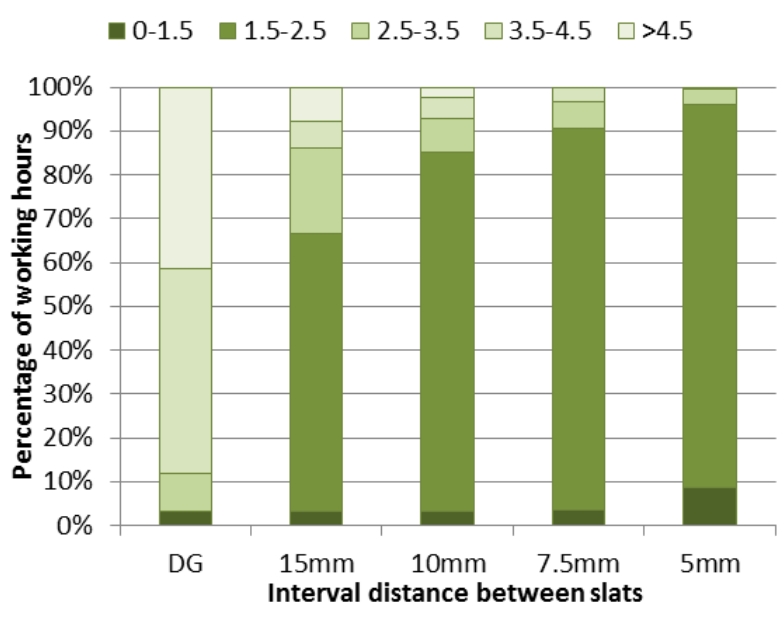

(a)

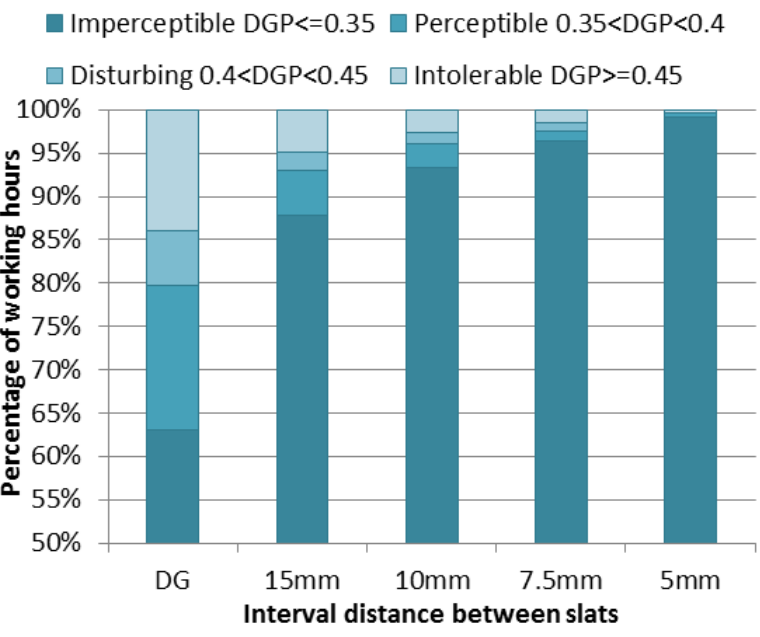

(b)

Figure 8: (a) Illuminance uniformity ratio (UR) (b) daylight glare probability (DGP) of window without and with diffuse translucent PS-TIM with 4 different slat pitches

In order to provide a more intuitive impression of the daylight distribution and glare in the office to accompany these metrics, false colour and true colour visualisations for noon on the $21^{\text {st }}$ March were generated and are shown in Figure 9. The presence of PS-TIM results in a more homogenous distribution of daylight and the level of homogeneity increases as the slat

11 pitch gets smaller.

\section{Equinox (March) 12pm}

\section{DG}
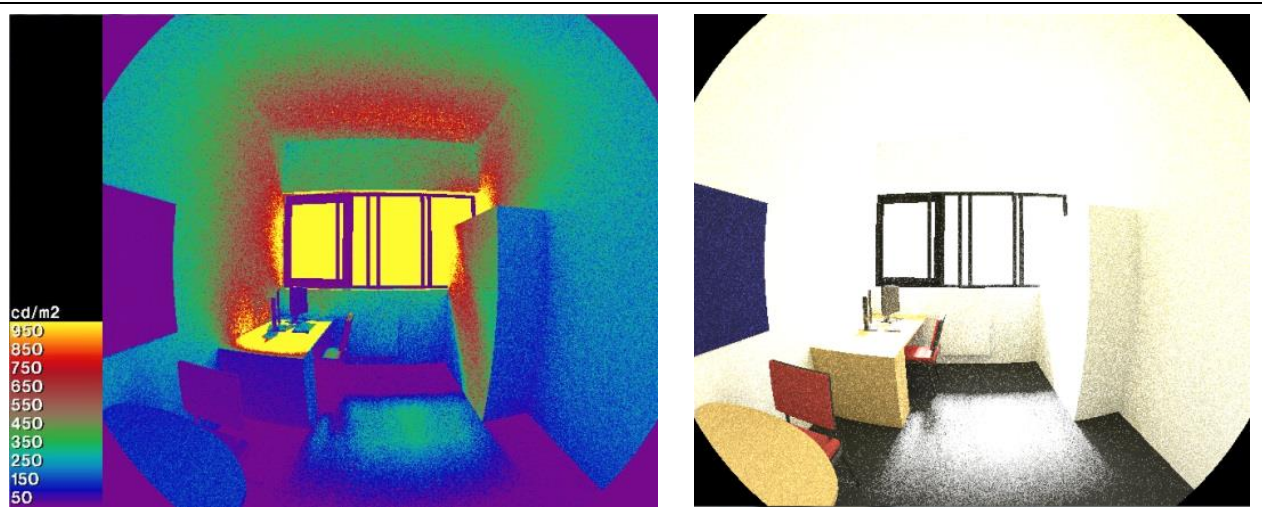

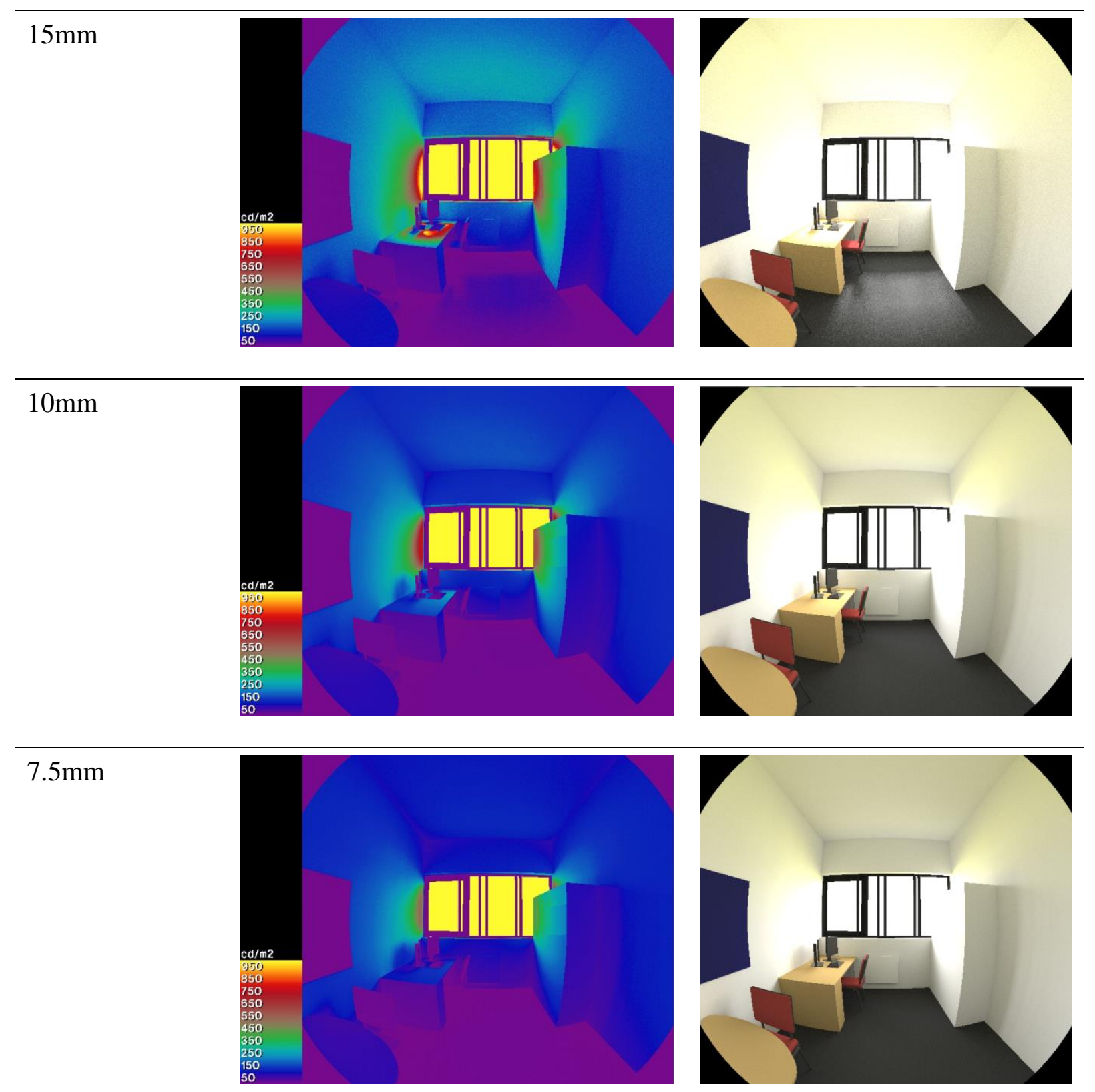

$5 \mathrm{~mm}$

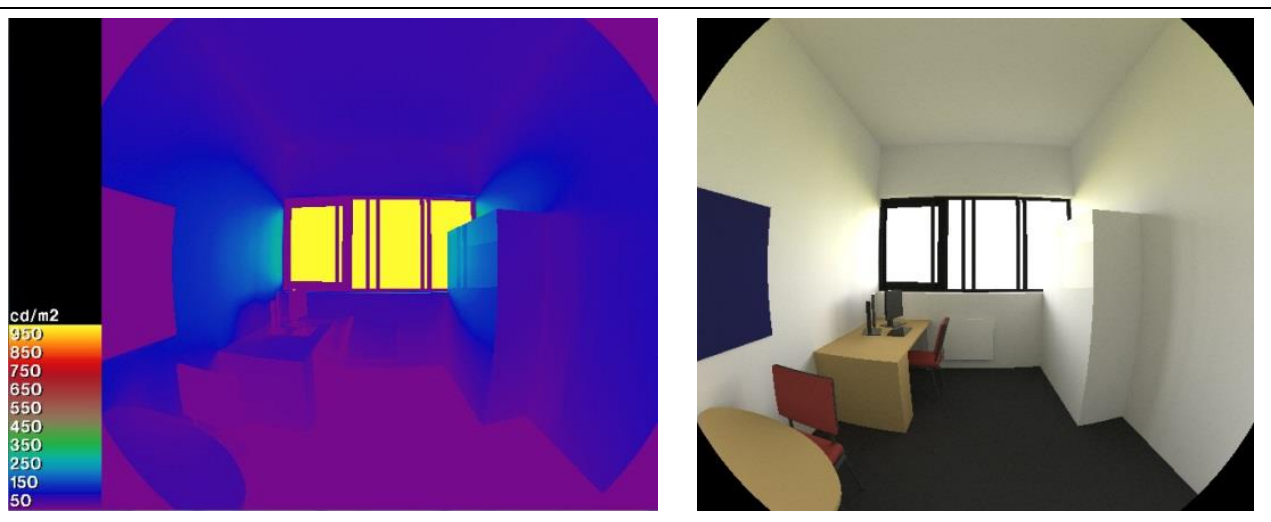

Figure 9: RADIANCE false colour and visualizations and associated DGPs for window with and without PS-TIM with different slat pitches for London on 21st March at 12pm under a CIE clear sky. 


\section{$1 \quad 4.2$ The effects of slat tilt angle on daylight performance}

In this section, simulation was undertaken for the PS-TIM with Lambertian diffuse

3 translucent slats placed with fixed slat pitch and the slat tilt angles, $(\phi)$, was varied between -

$460^{\circ}$ and $60^{\circ}$, (labelled as ' $-60^{\circ},{ }^{\circ}-45^{\circ},{ }^{\prime}-30^{\circ},{ }^{\prime} 0^{\circ},{ }^{\prime} 30^{\circ},{ }^{\circ} 45^{\circ}$ ' and ' $60^{\circ}$ ' respectively in

5 preceding discussions). Figure 10 shows the variation of illuminance $U R$ and $D G P$ for a 15

$6 \mathrm{~mm}$ PS-TIM at different tilt angles. This PS-TIM slat pitch was selected because it is the least

7 effective of the non-tilted configurations studied in section 4.1 (see Figure 10), therefore,

8 further investigations have been carried out to explore whether varying tilt angle has the

9 potential to improve its performance.

It can be seen in Figure 10 (a) and (b), that with the slats tilted at positive angles

11 relative to the sky vault (i.e. $\phi=30^{\circ}, 45^{\circ}$ and $60^{\circ}$ ), the performance was worse than that of the

PS-TIM with non-tilted slats in terms of both daylight $U R$ and $D G P$. Improved performance

13 can be observed in the data for slats with negative tilt angles if $U R<3.5$ and $D G P<0.4$ are

14 used as metrics. The percentage of working hours with $U R$ below 1:2.5 improves from $66 \%$

15 when slats are horizontally placed to $80 \%$ when slats are tilted at $-30^{\circ}$ and working hours with

$16 D G P$ below 0.35 improves from $87 \%$ when slats are horizontally placed to around $90 \%$ when

17 slats are tilted at angles of $-30^{\circ},-45^{\circ}$ and $-60^{\circ}$. 
$\square$ 0-1.5 $\square$ 1.5-2.5 $\square 2.5-3.5 \square 3.5-4.5 \square>4.5$

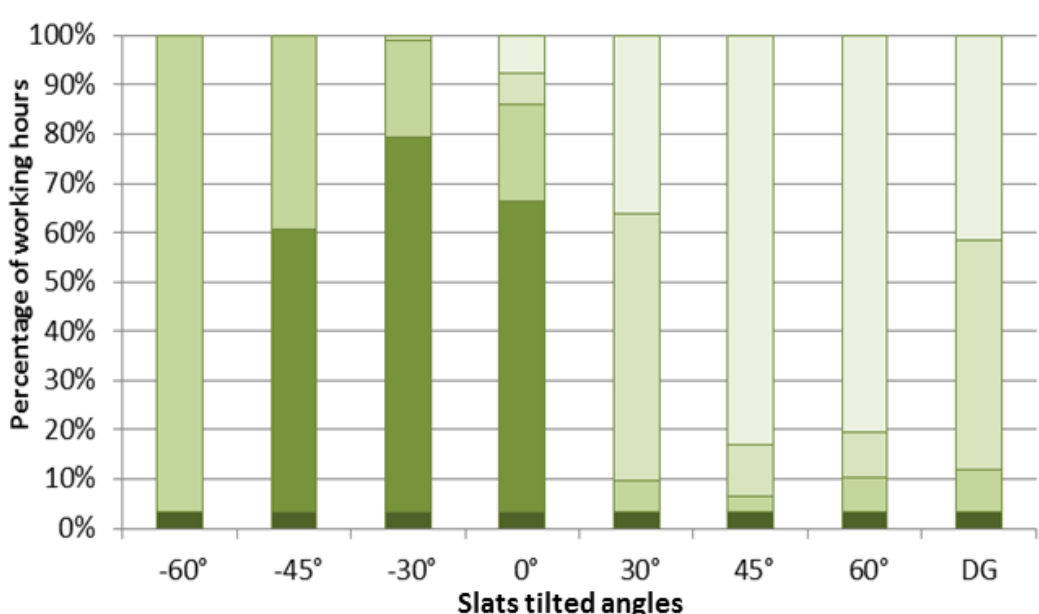

(a)

n Imperceptible DGP $<=0.35$ Perceptible $0.35<\mathrm{DGP}<0.4$

$\square$ Disturbing $0.4<\mathrm{DGP}<0.45 \square$ Intolerable DGP $>=0.45$

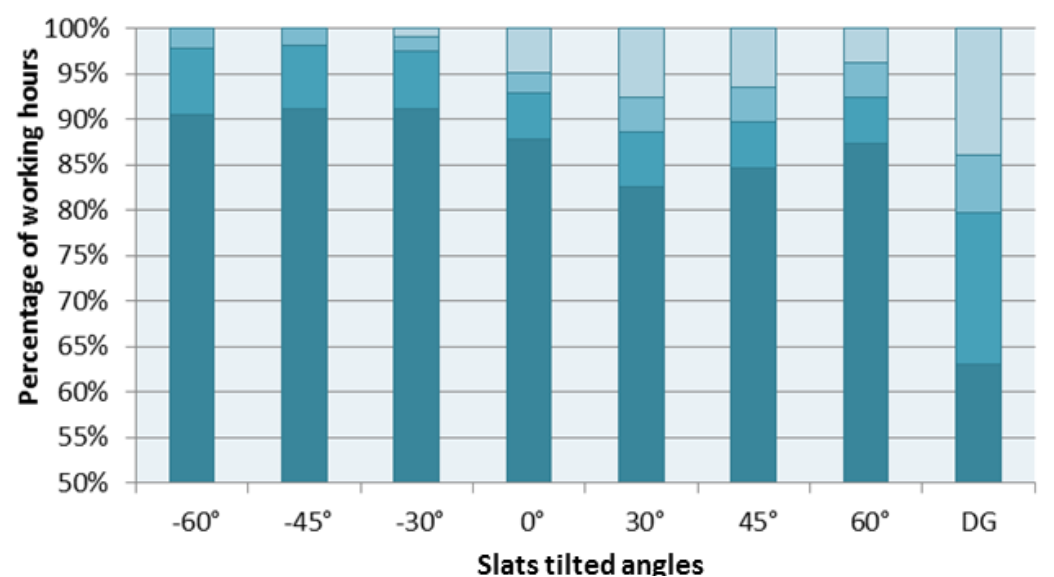

(b)
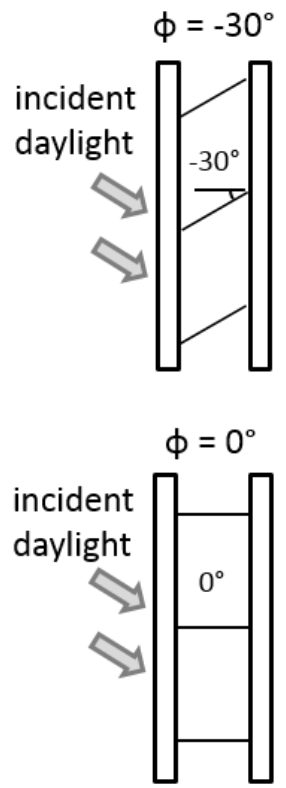

$\phi=30^{\circ}$

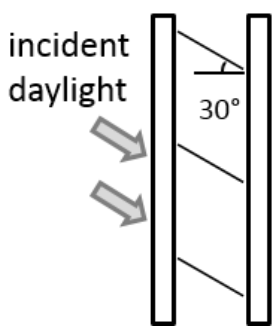

(c)

Figure 10: (a) Illuminance uniformity ratio (UR), (b) daylight glare probability (DGP) for a window with diffuse translucent PS-TIM with slat pitch of $15 \mathrm{~mm}$ at 7 different tilt angles, and (c) definition of tilt angles, $\phi$.

In terms of improving daylight comfort levels, Figure 10 also suggests that only PSTIM with a tilt angle of $-30^{\circ}$ offers improved comfort over horizontally placed slats. Section 4.1 indicated that the $7.5 \mathrm{~mm}$ PS-TIM was the optimised pitch configuration for improving both daylight availability and daylight comfort. On this basis, the performance of the $7.5 \mathrm{~mm}$ PS-TIM with $-30^{\circ}$ tilted slats and $7.5 \mathrm{~mm}$ PS-TIM with non-tilted slats (labelled as $0^{\circ}$ ) were compared in terms of daylight availability (i.e. $U D I_{100-2000}$ lux and $U D I_{500-2000 ~ l u x}$ ) as shown in Figure 11. When evaluating the $U D I$ in the range from 100 to 2000 lux, there is no significant difference between the $7.5 \mathrm{~mm}$ PS-TIM system with slats tilted at angles of $0^{\circ}$ and $-30^{\circ}$. For 
1 the most desired daylight range of 500 to 2000 lux, the $U D I$ values of these two tilt angles are

2 almost the same in the region close to the window (i.e. up to $1.7 \mathrm{~m}$ into the room). However,

3 at locations deeper within the room, the UDI values for PS-TIM with non-tilted slats remain

4 constant at around $50 \%$ of working hours, while those for the $-30^{\circ}$ tilted slats show a steady

5 decrease with only $30 \%$ of working hours indicating a favoured UDI. It can be concluded that

6 for the PS-TIM with slat pitch of $7.5 \mathrm{~mm}, 30^{\circ}$ tilted slats do not provide significant

7 improvement of daylight availability when compared with non-tilted slats.

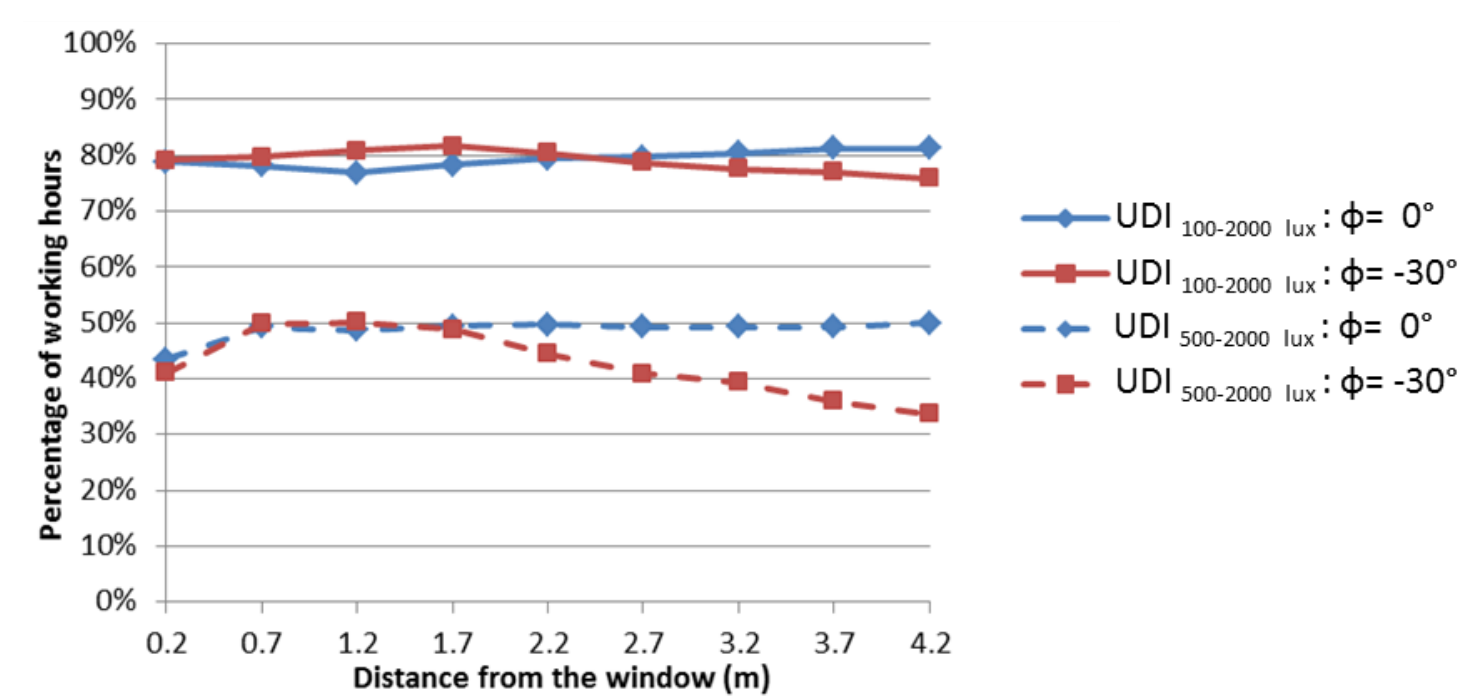

Figure 11: $U D I_{100-2000 ~ l u x}$ and $U D I_{500-2000}$ lux for diffuse translucent PS-TIM with $7.5 \mathrm{~mm}$ slat pitch at $0^{\circ}$ and $-30^{\circ}$ tilt angles

\section{$11 \quad 4.3$ The effects of slat material properties on daylight performance}

Sections 4.1 and 4.2 discussed the performance of PS-TIM with Lambertian diffuse translucent slats located in the air cavity between the two panes of a double glazing unit. The analysis was performed for various slat pitches (i.e. $15 \mathrm{~mm}, 10 \mathrm{~mm}, 7.5 \mathrm{~mm}$ and $5 \mathrm{~mm}$ ) and various tilt angles (i.e. $-60^{\circ},-45^{\circ},-30^{\circ}, 0^{\circ}, 30^{\circ}, 45^{\circ}$ and $60^{\circ}$ ) in a south facing office using the climatic data for London. This section repeats part of this analysis (i.e. $U D I, U R$ and $D G P$ )

17 but replaces the PS-TIM diffusing slats with a transparent material. 
1 Figure 12 (a) indicates that applying translucent PS-TIMs could increase the percentage of

2 working hours when the metrics lie in their desirable ranges (i.e. UDI in usefulbin, uniformity

3 below 2.5 and $D G P$ below 0.35 ) when compared with a standard double glazed window.

4 Figure 12 (b) shows the reduced percentage of working hours when the metrics lie in their 5 undesirable ranges (i.e. UDI in oversupplied bin, uniformity over 4.5 and DGP over 0.45 ) as

6 compared with the data for a standard double glazed window. As can be seen in Figure 12 (a),

7 the percentage of working hours during which the average UDI lies in the range of 100-2000

8 lux, $D G P \leq 3.5$ and $U R \leq 1: 2.5$ were $47 \%, 3 \%$ and $63 \%$ for standard double glazing unit.

9 These metrics can be increased by between $18 \sim 29 \%$ (UDI), up to $97 \%(U R)$ and $25 \sim 37 \%$

$10(D G P)$, respectively, when PS-TIMs are applied. In addition, for the undesired ranges of these

11 metrics, as shown in Figure 12 (b), the percentage of working hours when the average UDI is

12 over 2000 lux is $41 \%$ for the double glazing unit, and it can be reduced by between $21 \%$ and

$1340 \%$, depending on the type of PS-TIM used. There are $42 \%$ of working hours where the $U R$

14 is higher than 1: 4.5 and $14 \%$ of working hours where the $D G P$ is higher than 0.45 when

15 using a standard double glazing unit: these two undesired situations can be completely

16 eliminated by integrating translucent PS-TIMs.

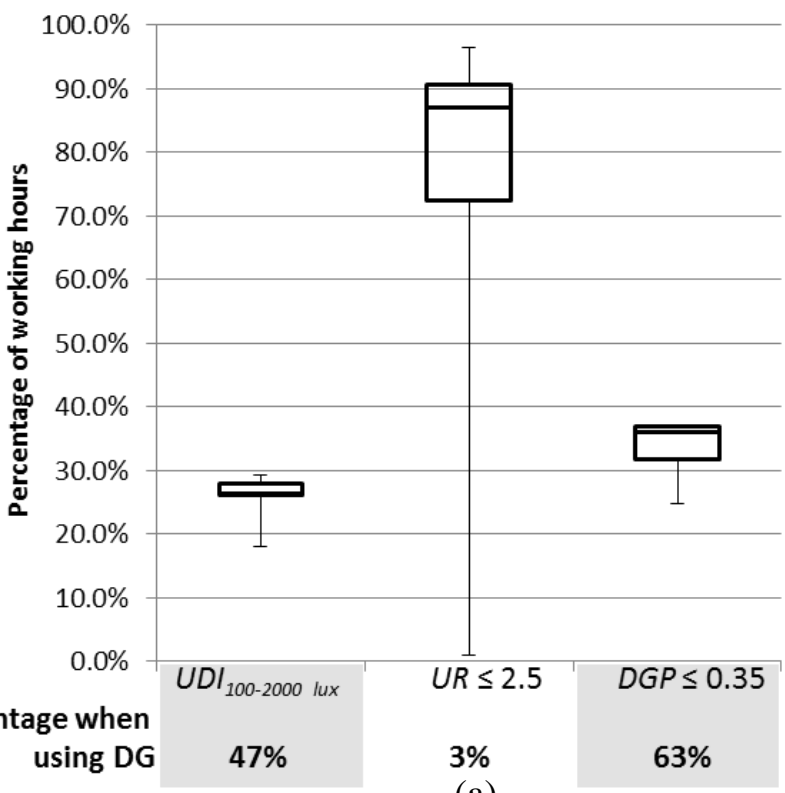

(a)
Percentage variation of using various translucent PS-TIMs (increase)

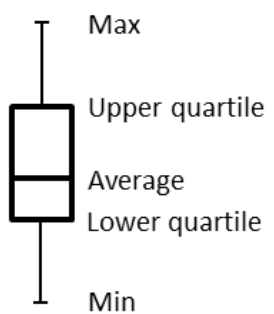




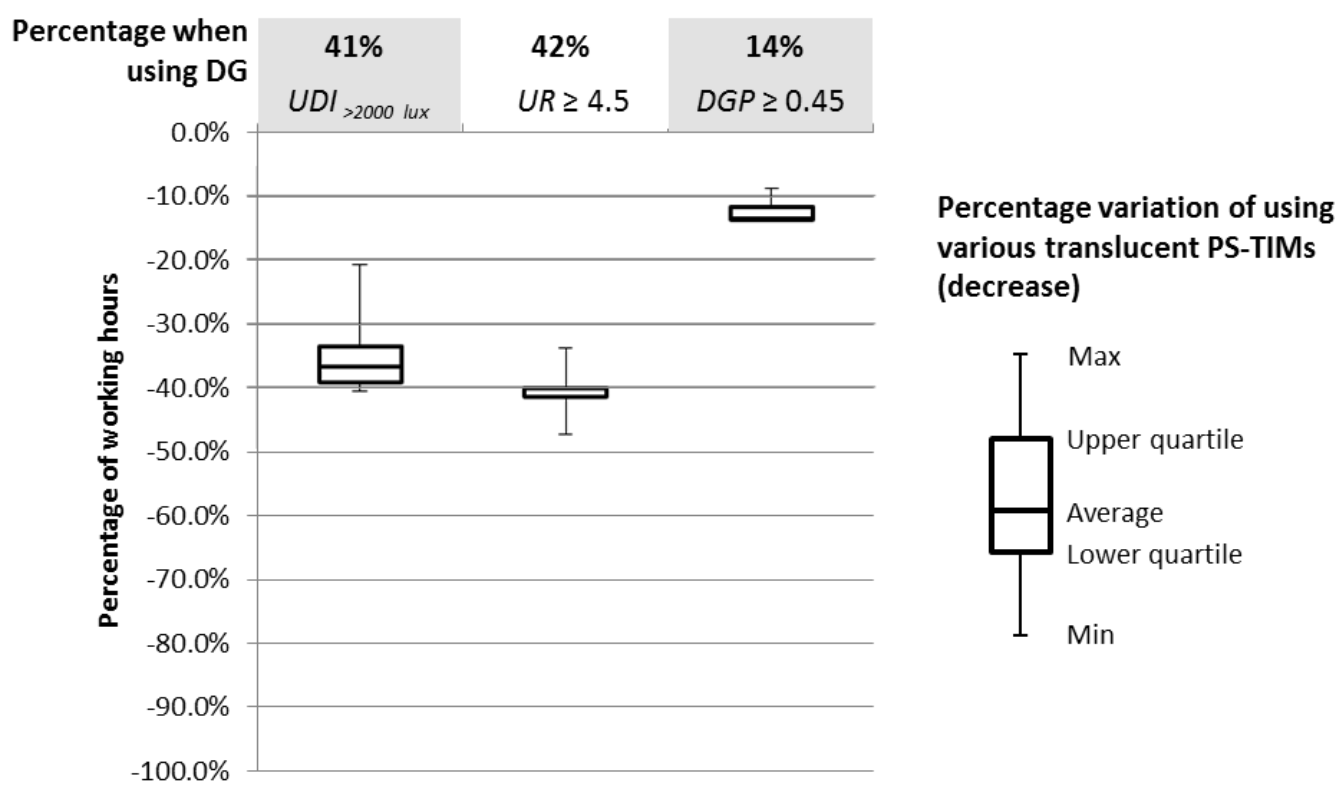

(b)

Figure 12: Summary of performance metrics for PS-TIMs with translucent slats in (a) desirable ranges and (b) undesirable ranges.

Figure 13 shows the $U R$ and $D G P$ after applying various configurations of PS-TIMs with transparent slats, and Table 5 shows the percentage of working hours where the UDI is in the range of 100-2000 lux. As can be seen from Table 5 and Figure 13, when comparing PSTIMs with non-tilted transparent slats to standard double glazing, the $5 \mathrm{~mm}$ PS-TIM provides the best performance in terms of reducing the percentage of working hours where the $U R$ is over 1: 4.5 (i.e. dropping from $42 \%$ to $24 \%$ ). It also increases the percentage of working hours with $D G P$ below 3.5 from $63 \%$ to $69 \%$, and slightly improves the percentage of working

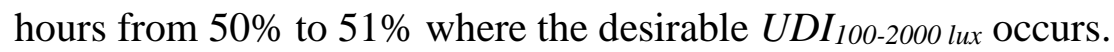

On the basis of these results, the slats with $5 \mathrm{~mm}$ pitch were then investigated at various tilt angles $\left(-60^{\circ},-45^{\circ},-30^{\circ}, 30^{\circ}, 45^{\circ}\right.$, and $\left.60^{\circ}\right)$ to identify an optimised configuration. However, the results indicated that there was no obvious improvement in $U R$ or $D G P$ as compared with the results for the non-tilted slats. Tilt angle has a slight impact on the illuminance distribution. The $-60^{\circ}$ tilted slats, which have the best overall performance, can improve the $U D I_{100-2000 l u x}$ by between $5 \%$ - 9\% of working hours and improve the 
1 imperceptible DGP $\leq 3.5$ by $11.5 \%$ of working hours as compared with the PS-TIM with

2 horizontal slats. However, the window with transparent PS-TIMs does not yield significant 3 improvement in either $U D I$ distribution, $U R$ or $D G P$ as compared with the standard double 4 glazed unit, the results for each being very similar.

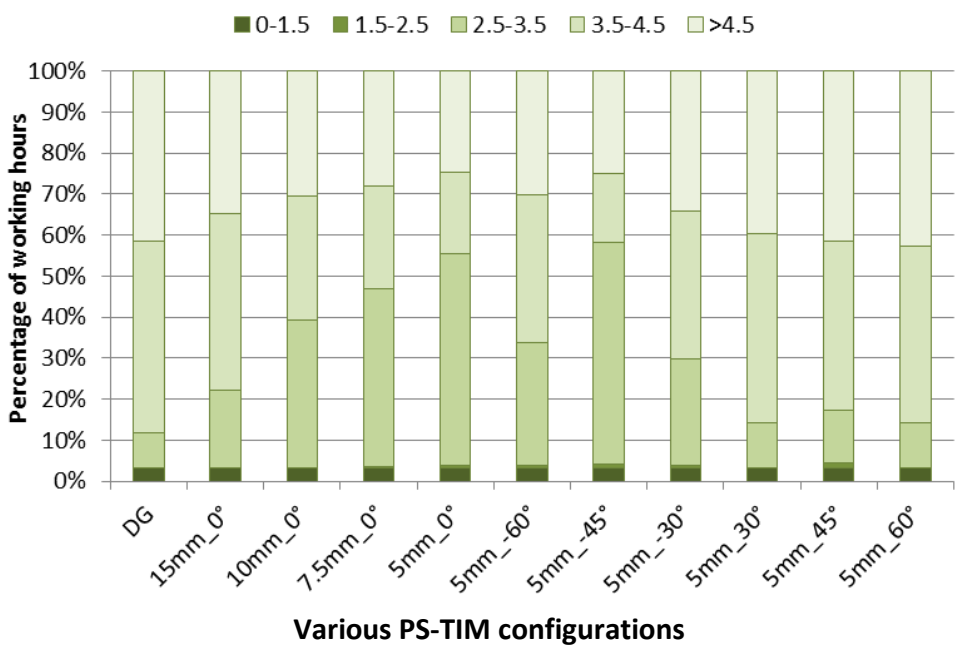

(a)

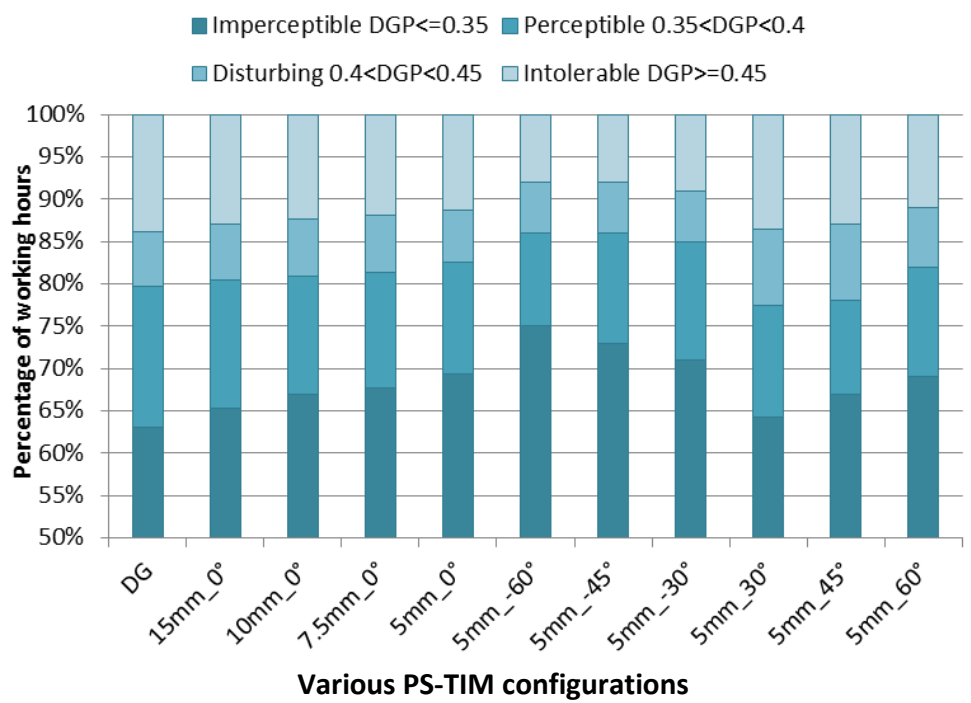

(b)

Figure 13: (a) Illuminance uniformity ratio (UR) (b) daylight glare probability (DGP) for a window with and without transparent PS-TIM for 4 different slat pitches at 7 different tilt angles. 

1 Table 5: UDI100-2000lux for a window with and without transparent PS-TIM for 4 different slat pitches at 7 different tilt
angles.

\begin{tabular}{lccccccccc}
\hline & 0.2 & 0.7 & 1.2 & 1.7 & 2.2 & 2.7 & 3.2 & 3.7 & 4.2 \\
\hline DG & $47 \%$ & $30 \%$ & $34 \%$ & $42 \%$ & $48 \%$ & $55 \%$ & $61 \%$ & $66 \%$ & $68 \%$ \\
\hline $15 \mathrm{~mm} \_0^{\circ}$ & $48 \%$ & $31 \%$ & $36 \%$ & $42 \%$ & $48 \%$ & $55 \%$ & $60 \%$ & $65 \%$ & $67 \%$ \\
$10 \mathrm{~mm} \_0^{\circ}$ & $49 \%$ & $32 \%$ & $37 \%$ & $43 \%$ & $48 \%$ & $55 \%$ & $60 \%$ & $65 \%$ & $67 \%$ \\
$7.5 \mathrm{~mm} \_0^{\circ}$ & $50 \%$ & $33 \%$ & $38 \%$ & $43 \%$ & $48 \%$ & $55 \%$ & $60 \%$ & $65 \%$ & $67 \%$ \\
\hline $5 \mathrm{~mm} 0^{\circ}$ & $51 \%$ & $34 \%$ & $38 \%$ & $43 \%$ & $49 \%$ & $55 \%$ & $61 \%$ & $65 \%$ & $67 \%$ \\
$5 \mathrm{~mm} \_30^{\circ}$ & $50 \%$ & $32 \%$ & $36 \%$ & $42 \%$ & $49 \%$ & $53 \%$ & $59 \%$ & $63 \%$ & $64 \%$ \\
$5 \mathrm{~mm} \_45^{\circ}$ & $46 \%$ & $32 \%$ & $37 \%$ & $42 \%$ & $50 \%$ & $56 \%$ & $63 \%$ & $67 \%$ & $69 \%$ \\
$5 \mathrm{~mm} \_60^{\circ}$ & $48 \%$ & $33 \%$ & $40 \%$ & $43 \%$ & $50 \%$ & $58 \%$ & $66 \%$ & $70 \%$ & $71 \%$ \\
$5 \mathrm{~mm} \_-30^{\circ}$ & $54 \%$ & $35 \%$ & $39 \%$ & $43 \%$ & $50 \%$ & $57 \%$ & $65 \%$ & $69 \%$ & $71 \%$ \\
$5 \mathrm{~mm} \_-45^{\circ}$ & $55 \%$ & $37 \%$ & $41 \%$ & $44 \%$ & $52 \%$ & $59 \%$ & $66 \%$ & $72 \%$ & $74 \%$ \\
$5 \mathrm{~mm} \_60^{\circ}$ & $55 \%$ & $38 \%$ & $42 \%$ & $46 \%$ & $53 \%$ & $61 \%$ & $68 \%$ & $75 \%$ & $76 \%$ \\
\hline
\end{tabular}




\section{5. Results and discussion of applying PS-TIM at different climates and for different room orientations}

The performance of the PS-TIM window systems is likely to be influenced by the latitude of the site which they are used on and the orientation of the glazing relative to the sun path. In addition, climatic influences that dictate the balance between clear skies with direct

sunlight and overcast skies with diffuse light also influence performance.

This section explores the daylight performance obtained from simulating PS-TIM performance using IWEC weather data for five cities viz Stockholm, London, Beijing, Hong Kong and Singapore. These represent different geographical locations and weather/solar conditions. In addition, the daylight performance for the prototype office facing four different orientations (East, West, South and North) located at London (a relatively high latitude site outside the Tropics) and Singapore (located within the Tropics, close to the equator) is also studied. In these studies, the PS-TIM comprises diffused translucent non-tilted slats contained within a double glazing unit. From section 4, slat pitch rather than slat tile angle showed the most significant effect on the daylight performance, therefore, the sole PS-TIM variable explored in this section. As in the previous sections, the useful daylight illuminance (UDI) was predicted at regular points located along the centre line of the room between the window to the end wall as indicated in Figure 4. The other two metrics, $U R$ and $D G P$, were not considered because PS-TIMs with all proposed slat pitches showed significant improvement of daylight performance in these two metrics.

\subsection{The application of PS-TIM in different climates}

Figure 14 (a) (e) shows the distribution of standard UDI bins used to quantify performance for the five different climates considered (these span a latitude range between 
1 bin size $\left(U D I_{500-2000 ~ l u x}\right)$, which captures only data that meet the design illuminance of at least

2500 lux. This provide greater detail than using the $U D I_{100-2000}$ lux bin alone.

The standard double glazed system shows similar daylight performance for each of the cities considered. In the region close to the window, a significant proportion of the working hours shows over illumination (i.e. appearing in the $U D I_{>2000}$ bin). As a consequence, only a small number of hours fall into the desirable levels of illumination (i.e. appearing in the UDI500-2000 lux bin). The inclusion of PS-TIM improves the luminous environment in the region close to the window by reducing the hours of over illumination and in so doing provides a more uniform illumination of the working plane. As can be seen in Figure 14 (a) and (b), the application of PS-TIMs with $7.5 \mathrm{~mm}$ and $5 \mathrm{~mm}$ slat pitch can provide relatively even 11 distribution of $U D I_{100-2000}$ lux and improve its proportion to approximately $70 \%$ and $80 \%$ of working hours in Stockholm and London, respectively. When using the additional criteria UDI500-2000 lux (as shown in Figure 14 (f) and (g)), it can be seen that with a decrease the slat pitch from $7.5 \mathrm{~mm}$ to $5 \mathrm{~mm}$, the percentage of working hours with illuminance in the most desired range reduced. Thus, PS-TIM with a $7.5 \mathrm{~mm}$ slat pitch provides the best all round performance in Stockholm and London. For Beijing, as shown in Figure 14 (c) and (h), the PS-TIM with a $5 \mathrm{~mm}$ slat pitch can improve the $U D I_{100-2000 \text { lux }}$ to around $90 \%$ of working hours and achieve a homogenous light distribution. However, when compared with PS-TIM with a $10 \mathrm{~mm}$ or $7.5 \mathrm{~mm}$ slat pitch, it performs worse in the illuminance range of 500-2000 lux, with a greater proportion of working hours falling in the range of 100-500 lux. The application of PS-TIMs with $7.5 \mathrm{~mm}$ and $5 \mathrm{~mm}$ slat pitch provide a relatively even

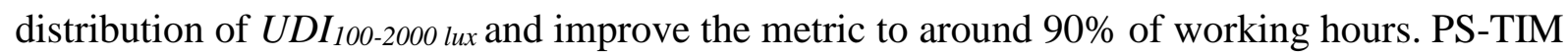
with a $10 \mathrm{~mm}$ slat pitch offer the best performance of $U D I_{500-2000}$ lux in Hong Kong (as shown in Figure 14 (d) and (i)). All but PS-TIM with $15 \mathrm{~mm}$ slat pitch can improve the illuminance in 
1 the range of 100-2000 lux to $90 \%$ of working hours in Singapore and PS-TIM with a $10 \mathrm{~mm}$

2 slat pitch performed best in the additional UDI 500-2000 lux criteria.

3 Generally, as latitude increases a smaller slat pitch is required to achieve optimised 4 performance and evenly distribute the daylight. For example, the $7.5 \mathrm{~mm}$ slat pitch PS-TIM 5 can provide relatively even distribution of $U D I_{500-2000 \text { lux }}$ and $U D I_{100-2000 \text { lux }}$ when applied in 6 London, and PS-TIM with a 10mm slat pitch can achieve similar effect when used in 7 Singapore. This is a consequence of the relationship between solar altitude and the pass angle 8 for the PS-TIM (i.e. $\tan ^{-1}$ (slat pitch / cavity width)). This dictates whether direct solar 9 radiation can reach the working plane in the region close to the window or whether this light 10 is incident on the slat and diffused. It is worth noting that for Beijing, only the PS-TIM with a $115 \mathrm{~mm}$ slat pitch can achieve a homogenous distribution of $U D I_{100-2000}$ lux. This is because the 12 direct solar irradiation is strong in the year of IWEC weather data (as shown in Appendix A) 13 and leads to significant numbers of hours of over supply (i.e. $U D I>2000 l u x$ ) despite undergoing 14 attenuation in the diffusing PS-TIM. To conclude, both the solar irradiation intensity and the solar altitude angle affect the process of selecting an optimal slat pitch for a window integrating with PS-TIM. 


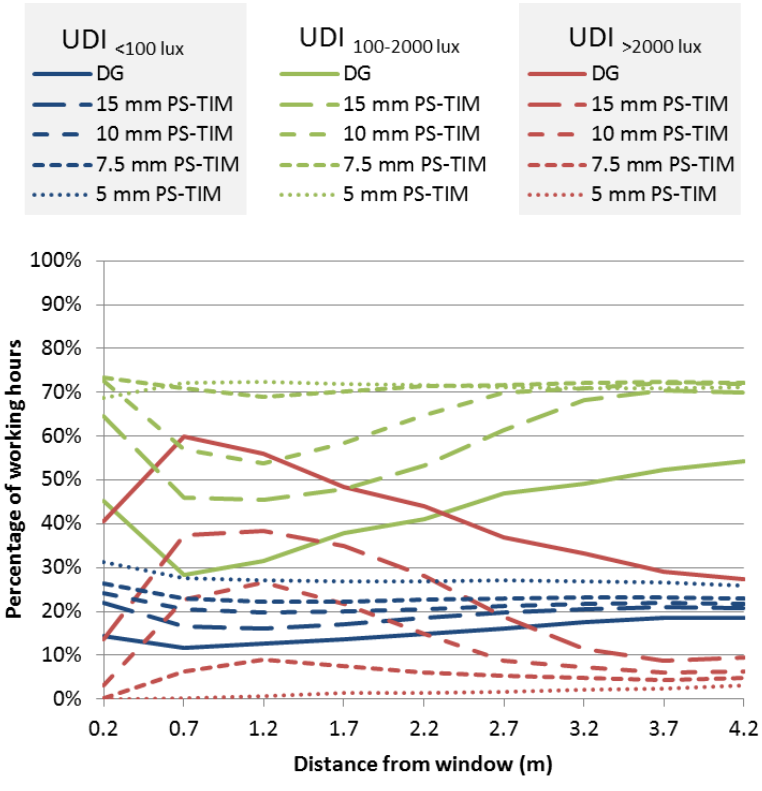

(a) Stockholm UDI bins

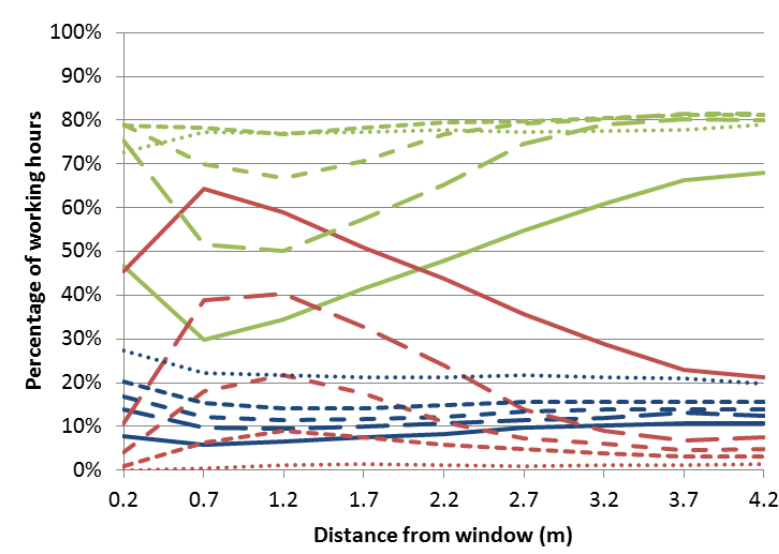

(b) London UDI bins

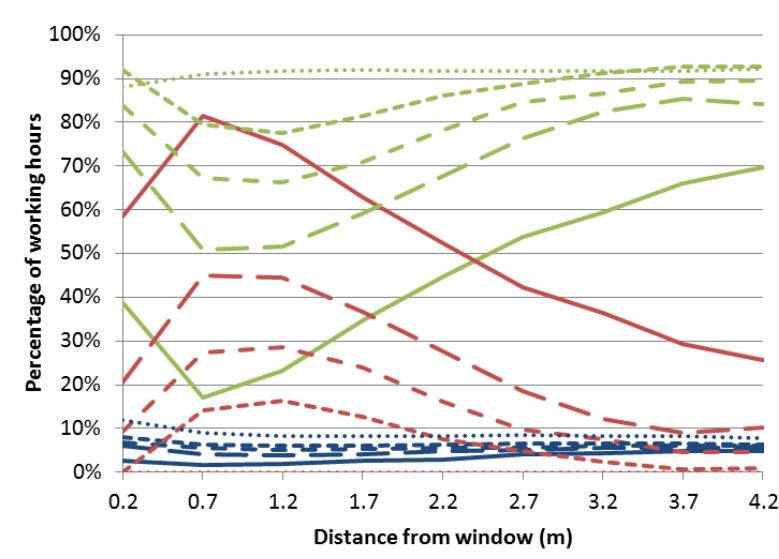

(c) Beijing UDI bins
UDI 500-2000 lux
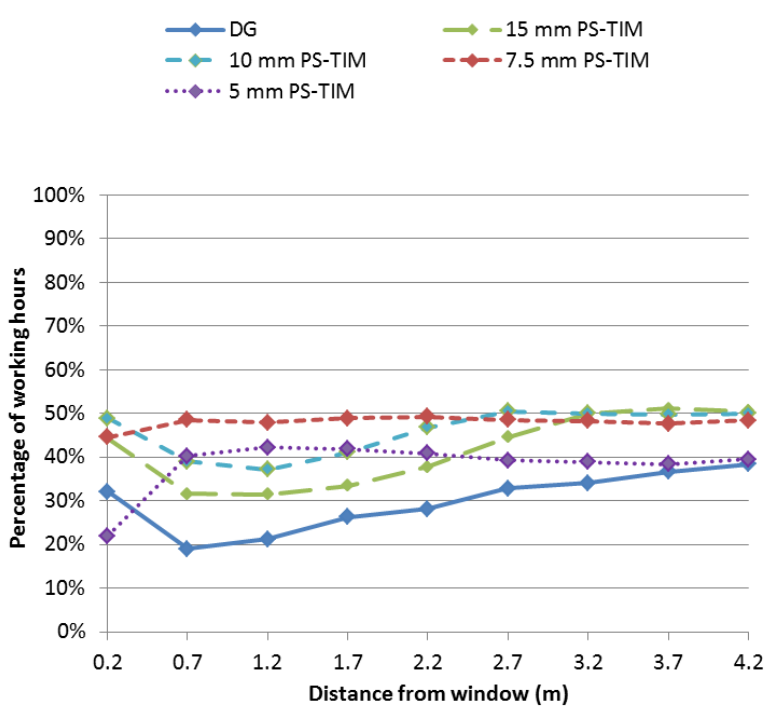

(f) Stockholm UDI $500-2000 l u x$

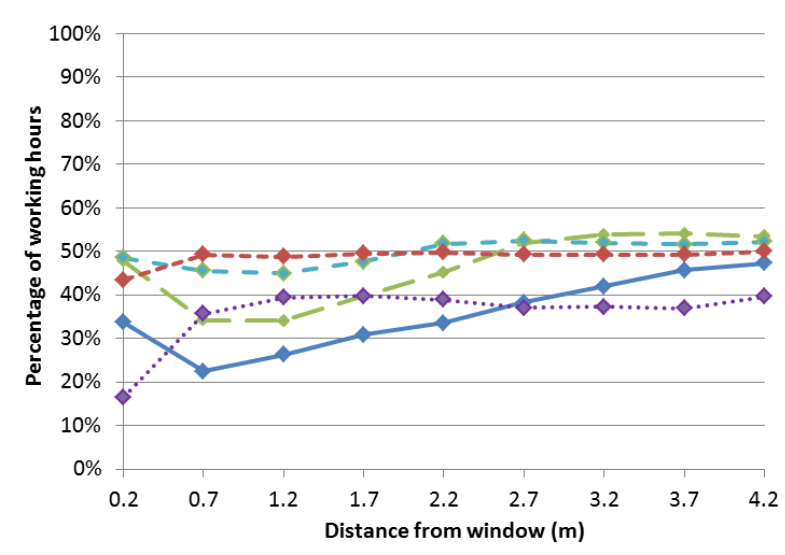

(g) London UDI500-2000lux

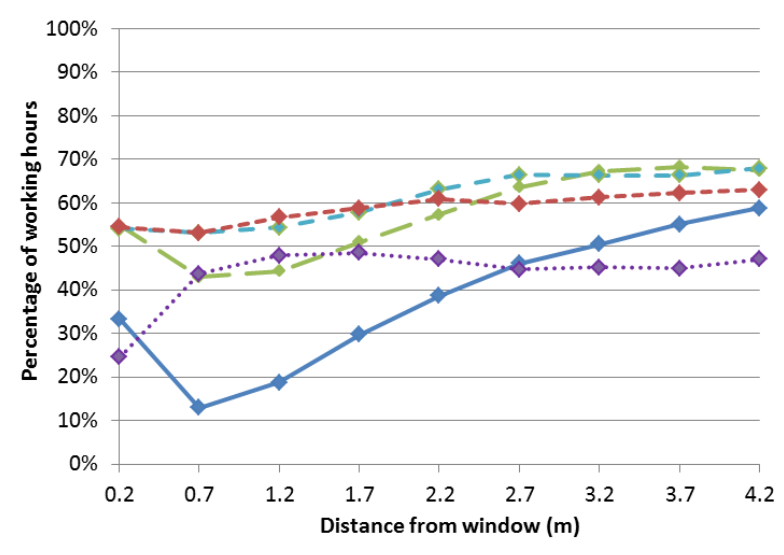

(h) Beijing UDI500-2000lux 


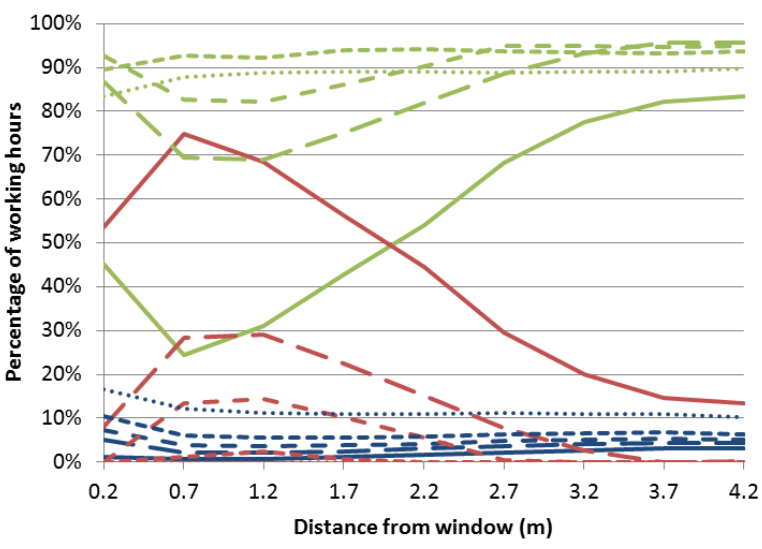

(d) Hong Kong UDI bins

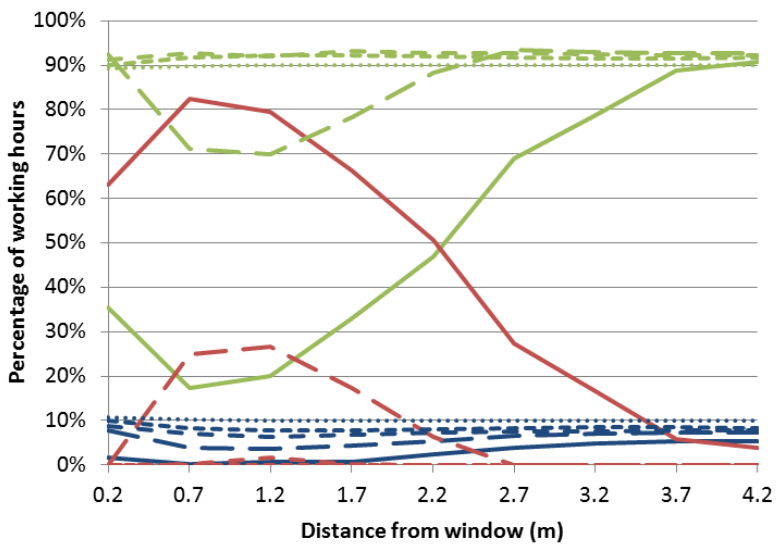

(e) Singapore UDI bins

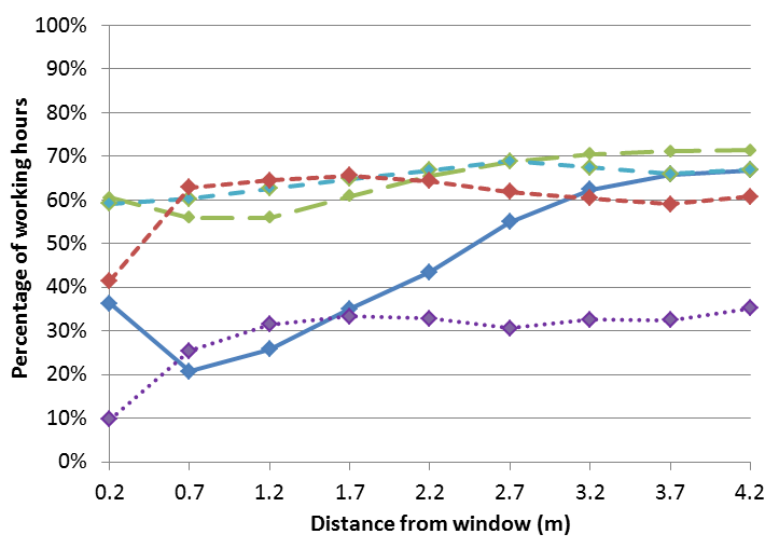

(i) Hong Kong $U D I_{500-2000 l u x}$

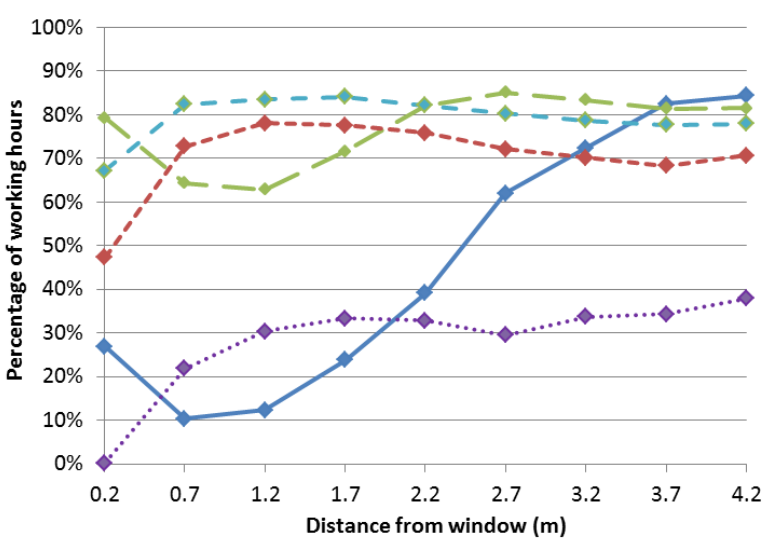

(j) Singapore $U D I_{500-2000 l u x}$

Figure 14: (a-e) standard three $U D I$ bins and (f-j) $U D I_{500-2000}$ lux bin at points along central line from south-facing window to end wall with and without PS-TIM with 4 different slat pitches under 5 different climate conditions: (a) and (f) Stockholm, (b) and (g) London, (c) and (h) Beijing, (d) and (i) Hong Kong, and (e) and (j) Singapore, 


\section{$1 \quad$ 5.2 The application of PS-TIM to windows with differing orientation}

The studies thus far in this paper have focused on equator facing facades. These are

subject to highest altitude direct solar irradiation in the sun path. This section explores glazing positioned in east and west facades, where lower altitude morning and evening sun predominates, as well as north facing facades, where for the sites chosen in this study, diffuse light tends to dominate.

In this section, only the useful bin (100 2000 lux $)$ of common three bins UDI metric is explored to provide an approximate picture of daylight performance. For a south facing window in London, as shown in Figure 15 (a), the $7.5 \mathrm{~mm}$ PS-TIM provides an even distribution and the highest percentage of operating hours (80\%) with a useful $U D I_{100-2000}$ lux . The north-facing façade mainly receives diffuse skylight rather than direct sunlight, thus, as shown in Figure 15 (b), PS-TIM with any slat pitch can provide a homogenous distribution of $U D I_{100-2000}$ lux with the $15 \mathrm{~mm}$ slat pitch providing the highest percentage of $U D I_{100-2000}$ lux being met. For the east and west orientation, the direct solar radiation is incident on the façade at low altitude angles for a short period after sunrise or before sunset and the radiation is not generally as strong as radiation incident on the south façade at noon. Under these conditons, $10 \mathrm{~mm}$ PS-TIM is sufficient to achieve a homogenous distribution of light and the highest level of $U D I_{100-2000}$ lux (Figure 15 (c) and (d)). Summarising, for cities with relatively high latitude (e.g. London), the south facing façade requires the smallest PS-TIM slat pitch to maximise useful daylight levels and distribution. Larger slat pitches can be used on the east and west facing façades, while the north facing façade can achieve comfortable daylight using the PS-TIM with largest slat pitch (in this case the $15 \mathrm{~mm}$ slat pitch). 


\begin{tabular}{|c|c|c|c|c|c|c|}
\hline UDI $<100$ lux & $\longrightarrow$ DG & -- & 15 mm PS-TIM & --- & 10 mm PS-TIM & …….. 7.5 mm PS-TIM \\
\hline UDI $_{100-2000 \mathrm{lu}}$ & DG & -- & 15 mm PS-TIM & --- & 10 mm PS-TIM & ............ 7.5 mm PS-TIM \\
\hline UDI >2000 lux & DG & -- & $15 \mathrm{~mm}$ PS-TIM & --- & 10 mm PS-TIM & ............ 7.5 mm PS-TIM \\
\hline
\end{tabular}

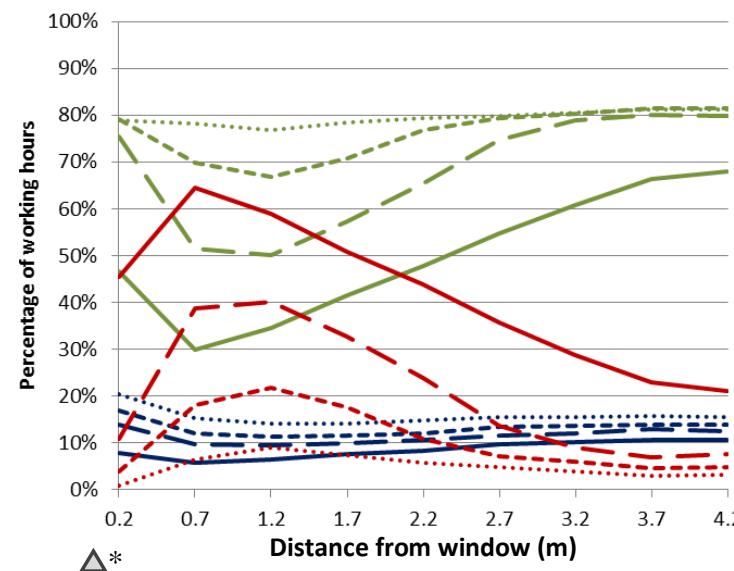

(a) SOUTH orientation

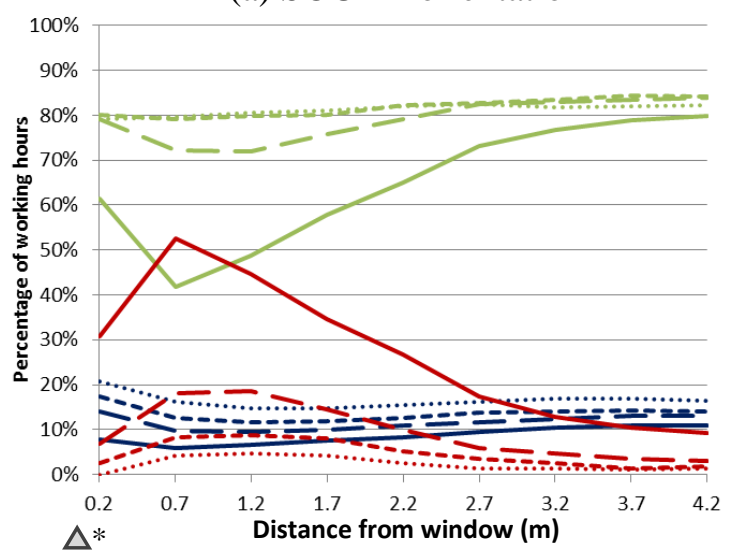

(c) WEST orientation

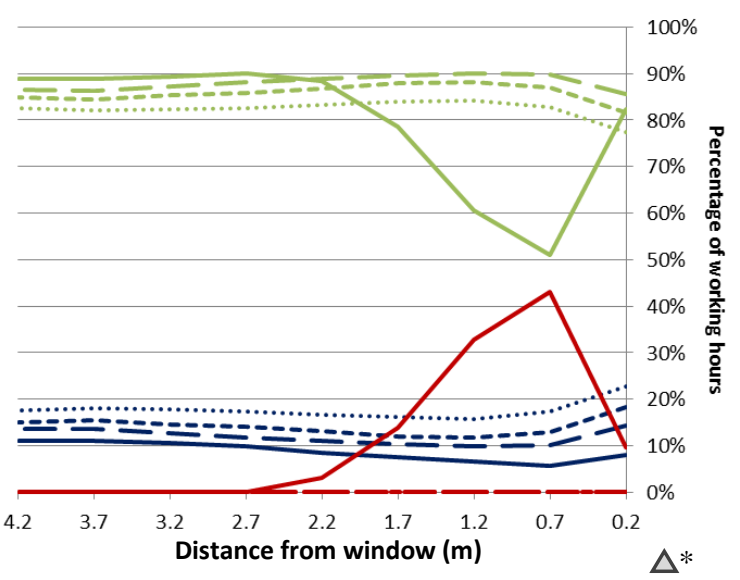

(b) NORTH orientation

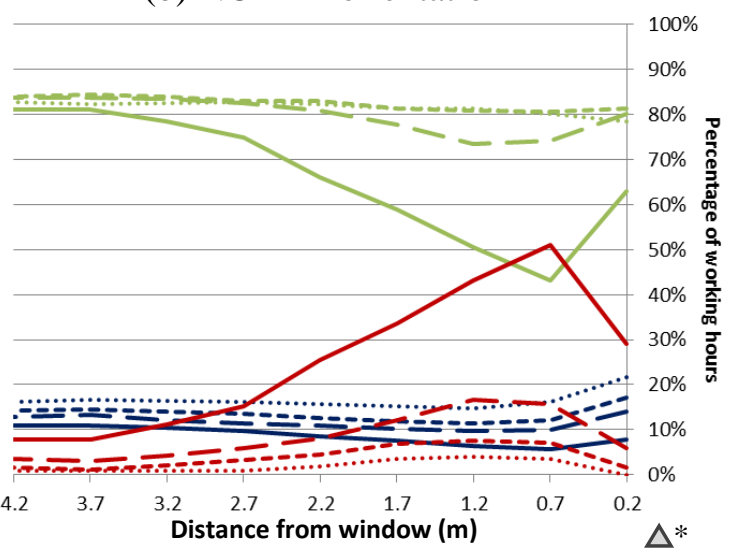

(d) EAST orientation

Figure 15: UDI bins for points along central line from window to end wall with (a) south, (b) north, (c) west, and (d) east window orientations with and without PS-TIM with 3 different slat pitches under London climate condition.

Singapore (see Figure 16), lies in the Tropics near the equator. As a consequence, the noon solar altitude is high (i.e. over $65^{\circ}$ ) all over the year and the sunlight is incident on the north and south facades depending on the season. Similar to the conditions in London, the sunlight with relatively low solar altitude is incident on east and west facades in the early morning and late afternoon respectively and has the potential to penetrate deeper into rooms,

11 often with high irradiation levels. Thus, compared with south and north facing façades, where PS-TIM with a $10 \mathrm{~mm}$ slat pitch is sufficient to deliver a homogenous distribution of $U D I_{100 \text { - }}$ $2000 l u x$, the east and west facing façades require PS-TIM with $7.5 \mathrm{~mm}$ slat pitch to achieve

14 similar effect. It can be concluded that, for cities with relatively low latitude (e.g. Singapore), 
$1 \quad$ PS-TIM applied to east and west facing façades, requires smaller slat pitches than PS-TIMs

2 applied to south and north facing façades.

3

\begin{tabular}{|c|c|c|c|c|c|c|}
\hline UDI $<100$ lux & $\longrightarrow$ DG & -- & 15 mm PS-TIM & --- & 10 mm PS-TIM & …….. 7.5 mm PS-TIM \\
\hline UDI $100-2000$ lux & DG & -- & 15 mm PS-TIM & --- & 10 mm PS-TIM & $\ldots \ldots \ldots \ldots . . .5 \mathrm{~mm}$ PS-TIM \\
\hline $\mathrm{UDI}_{>2000 \mathrm{lux}}$ & $\longrightarrow$ & -- & $15 \mathrm{~mm}$ PS-TIM & --- & 10 mm PS-TIM & ............. 7.5 mm PS-TIM \\
\hline
\end{tabular}

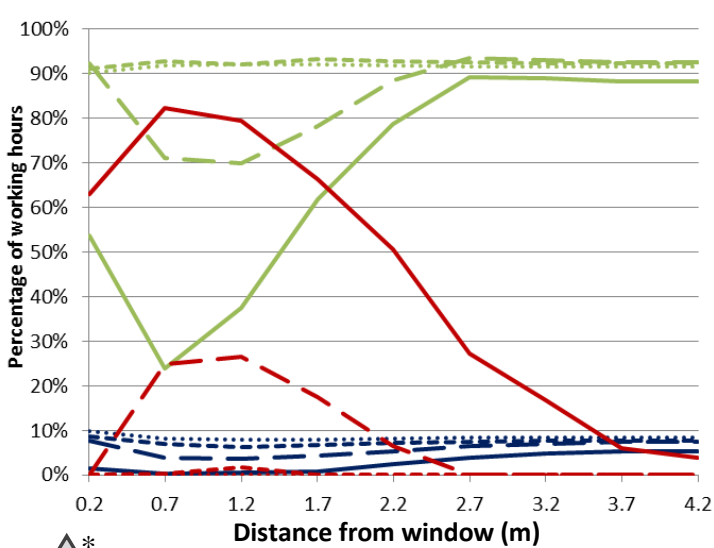

$\Delta^{*}$

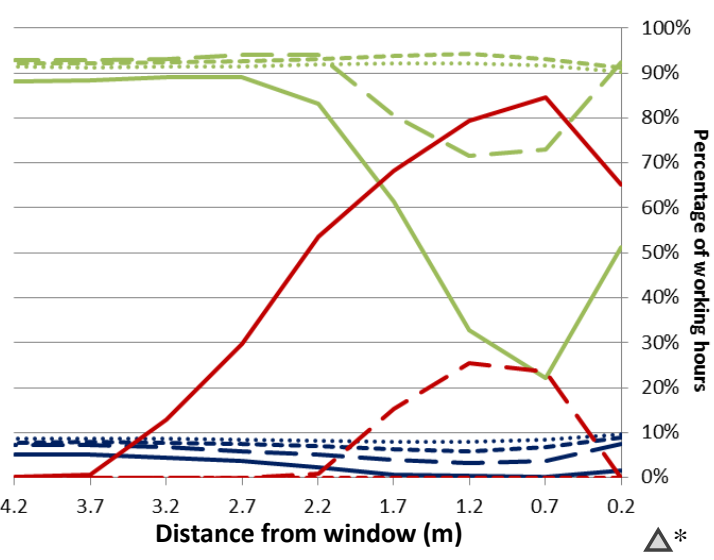

(b) NORTH orientation

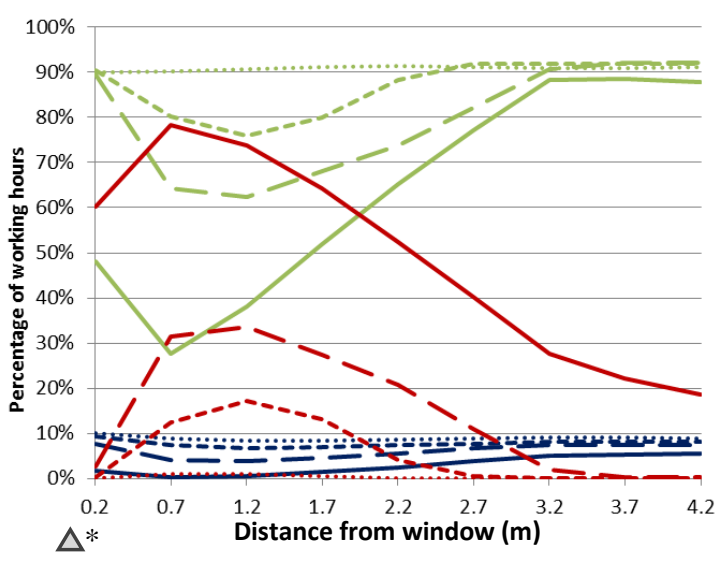

(c) WEST orientation

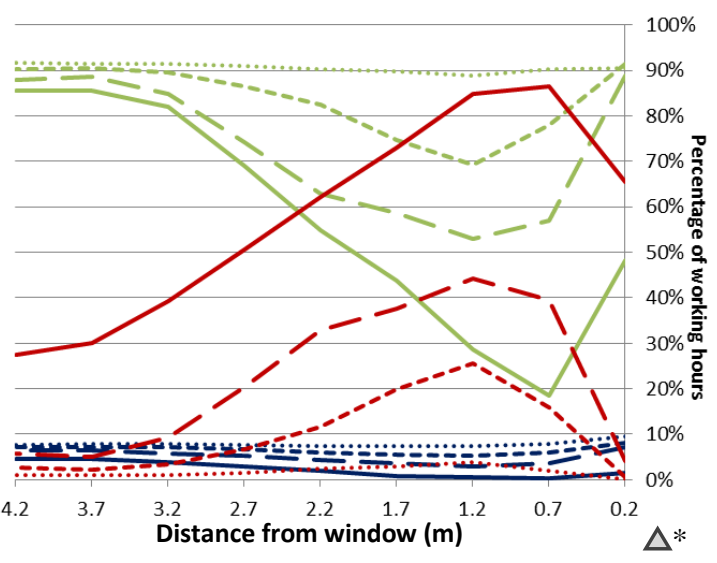

(d) EAST orientation

7 Figure 16: UDI bins at points along central line from window to end wall with (a) south, (b) north, (c) west, and (d) 8 east window orientations with and without PS-TIM with 3 different slat pitches under Singapore climate condition. 


\section{6. Conclusion}

An investigation of the daylight performance of a double glazed window with integrated parallel slat transparent insulation materials PS-TIMs, for a range of different sites and window orientations was conducted using RADIANCE in combination with Bidirectional Scattering Distribution Functions (BSDFs) to represent the PS-TIMs' optical performance. The following conclusions can be drawn:

1) PS-TIMs with translucent slats offer better performance than PS-TIMs with transparent slats in terms of Useful Daylight Illuminance (UDI), uniformity ratio (UR) and Daylight Glare Probability (DGP);

2) when compared with standard double glazing, glazing with integrated PS-TIM can increase the percentage of working hours when the UDI lies in the range of 100-2000 lux by between $47 \%$ and $79 \%$ depending on the type of the PS-TIM used, achieve a homogenous distribution of daylight, and effectively reduce the risk of glare;

3) the use of PS-TIMs at different latitudes suggested that with increasing latitude, a smaller slat pitch is required to maximise useful daylight $\left(U D I_{100-2000 l u x}\right)$ and evenly distribute the daylight. The intensity of solar radiation and the balance of time where clear or overcast skies prevail affect the process of identifying an optimal PS-TIM configuration. While some observations are made, the relationships are not quantified in this study;

4) when applying PS-TIMs to windows with different orientations a general observation for sites located outside of the Tropics is that the smallest slat pitch is required on the equator facing façade, east/west facades provide daylight with a slightly larger pitches and facades facing away from the equator can operate effectively with the largest slat pitch. For sites within the Tropics, north and south facades receive direct irradiation and the slat pitch required is likely to reflect the relative exposure of the two facades ranging from equal on 
the equator to relatively smaller pitches on the equator facing façade as you move away

2 from the equator.

This study has restricted itself to exploring the effect of PS-TIM on indoor daylight

4 level. Their influence on the overall energy performance will be presented in further research

5 papers.

The effects that PS-TIM has on the view into and out of a building are not considered

7 in this study. As part of an overarching glazing strategy, PS-TIM may therefore be usefully

8 used to maintain the external appearance of a glazed façade and admit daylight above and

9 below any regions of a façade reserved for maintaining view out of or into a building, where

10 conventional glazing would be more appropriate.

11

\section{Acknowledgements}

This work was supported by the Faculty of Engineering, University of Nottingham

14 and the China Scholarship Council through a joint $\mathrm{PhD}$ studentship awarded to Yanyi Sun. 


\section{Appendix A:}

2 The diurnal average direct and diffuse solar radiation of (a) Stockholm, (b) London, (c) Beijing, (d) Hong 3 Kong and (e) Singapore

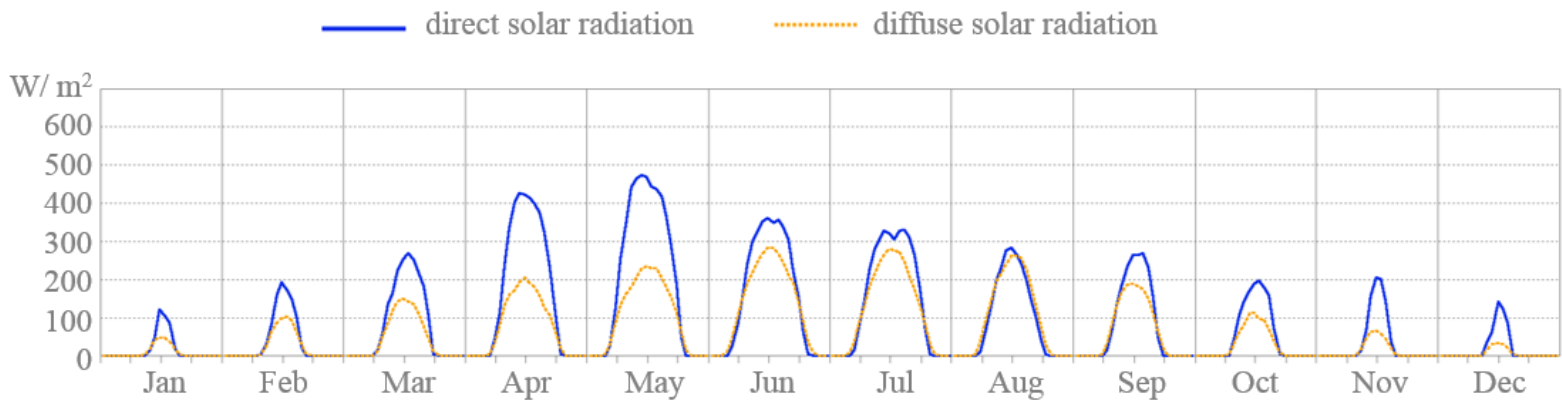

(a) More direct solar radiation than diffuse solar radiation in Stockholm's climate

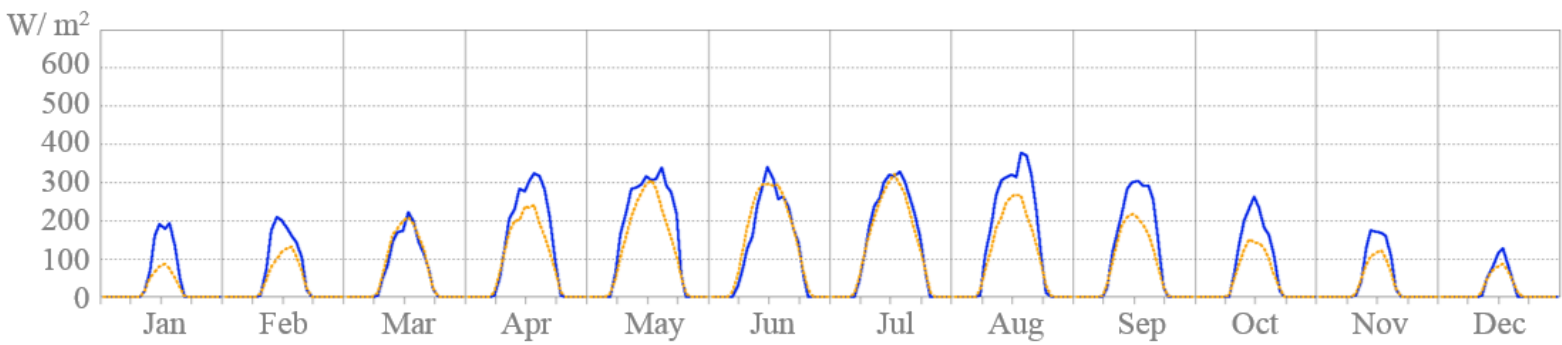

(b) Approximately equal direct and diffuse solar radiation in London's climate

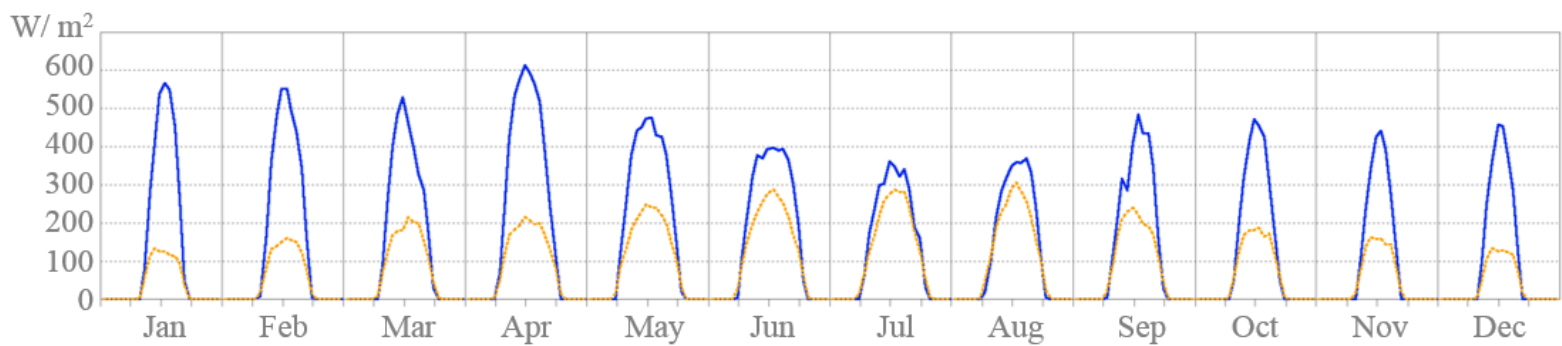

(c) Very strong direct solar radiation in winter, skies diffuse in summer in Beijing's climate

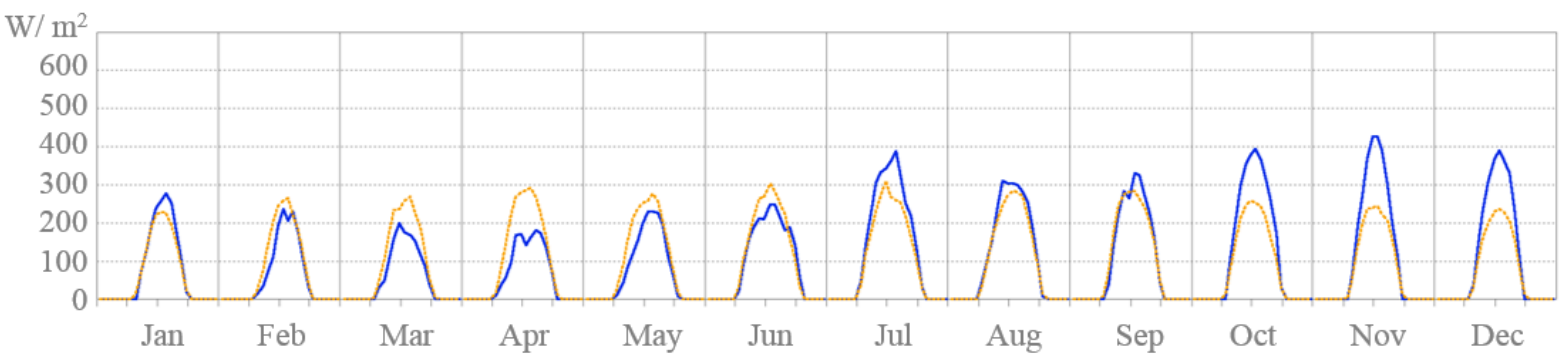

(d) Approximately equal direct and diffuse solar radiation in Hong Kong's climate

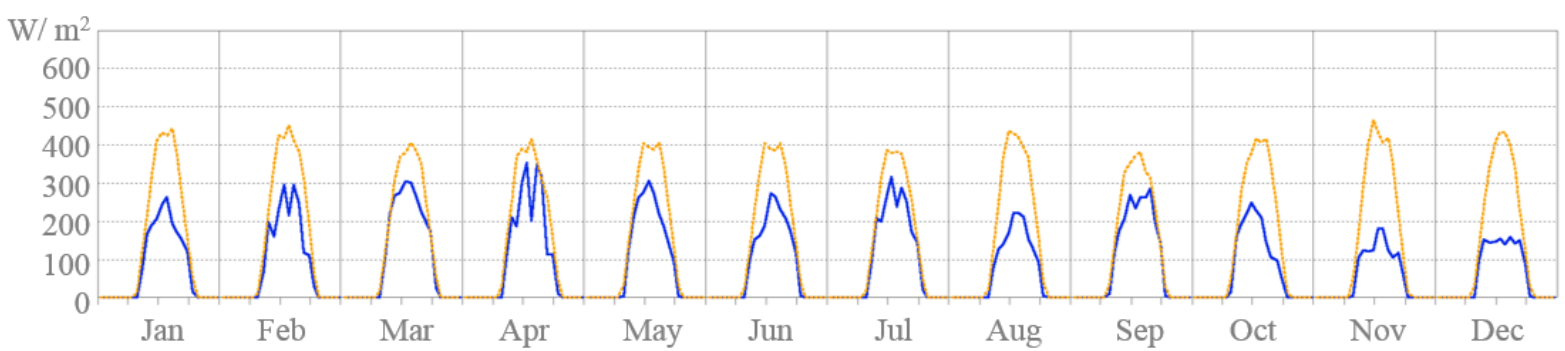

(e) Diffuse solar radiation greater than direct throughout the year in Singapore's climate 
2 1. SHC, Daylight in Buidling, in ECBCS Annex 29/ SHC Task 21 Project Summary

2. Pellegrino, A., Traditional and new metrics for effective daylighting design, in Advanced Builidng Skins, Energy Forum. 2013: Bressanone, Italy.

3. Sun, Y., et al., Thermal evaluation of a double glazing façade system with integrated Parallel Slat Transparent Insulation Material (PS-TIM). Energy and Buildings, 2016. In Press.

4. Wienold, J., Dynamic daylight glare evaluation., in Builing simulation 2009 the 11th international IBOSA conference. 2009: Glasgow, UK. p. 44-51.

5. Wienold, J., Dynamic simulation of blind control strategies for visual comfort and energy balance analysis., in Building simulation 2007, the 10th international IBOSA conference. 2007: Beijing, China. p. 1197-204.

6. Nabil, A. and J. Mardaljevic, Useful daylight illuminances: A replacement for daylight factors. Energy and Buildings, 2006. 38(7): p. 905-913.

7. Mangkuto, R.A., M. Rohmah, and A.D. Asri, Design optimisation for window size, orientation, and wall reflectance with regard to various daylight metrics and lighting energy demand: A case study of buildings in the tropics. Applied Energy, 2016. 164: p. 211-219.

8. Kapsis, K., V. Dermardiros, and A.K. Athienitis, Daylight Performance of Perimeter Office Façades utilizing Semi-transparent Photovoltaic Windows: A Simulation Study. Energy Procedia, 2015. 78: p. 334-339.

9. Berardi, U. and H.K. Anaraki, Analysis of the Impacts of Light Shelves on the Useful Daylight Illuminance in Office Buildings in Toronto. Energy Procedia, 2015. 78: p. 1793-1798.

10. Li, L., M. Qu, and S. Peng, Performance evaluation of building integrated solar thermal shading system: Building energy consumption and daylight provision. Energy and Buildings, 2016. 113: p. 189-201.

11. Bellia, L., A. Pedace, and F. Fragliasso, The role of weather data files in Climatebased Daylight Modeling. Solar Energy, 2015. 112: p. 169-182.

12. M. Saxena, et al., Dynamic RADIANCE - Predicting annual daylight with variable fenestratio optics using BSDFs, in Fourth National Conference of IBPSA-USA. 2010: New York City, USA.

13. Reinhart, $\mathrm{C}$. and S. Herkel, The simulation of annual daylight illuminance distributions - a state-of-the-art comparison of six RADIANCE-based methods. Energy and Buildings, 2000. 32(2): p. 167-187.

14. Reinhart, C. and O. Walkenhorst, Validation of dynamic RADIANCE-based daylight simulations for a test office with external blinds. Energy and Buildings, 2001. 33(7): p. 683-697.

15. Reinhart, C. and M. Andersen, Development and validation of a Radiance model for a translucent panel. Energy and Buildings, 2006. 38(7): p. 890-904.

16. Ward, G., et al., Simulating the daylight performance of Complex Fenestration Systems using Bidirectional Scattering Distribution Functions within Radiance. Journal of the Illuminating Engineering Society of North America 2011. 7(4).

17. Konstantoglou, M., J. Jonsson, and E. Lee, Simulating Complex Window Systems using BSDF Data, in 26th Conference on Passive and Low Energy Architecture. 2009: Quebec City, Canada. 
18. de Boer, J., Modelling indoor illumination by complex fenestration systems based on bidirectional photometric data. Energy and Buildings, 2006. 38(7): p. 849-868.

19. CF. Reinhart and VRM. LoVerso, A rules of thumb-based design sequence for diffuse daylight. Lighting Research and Technology, 2010. 42(1): p. 7-31.

20. CF. Reinhart, Daylight performance predictions, in Building performance simulation for design and operation Jan L.M. Hensen and R. Lamberts, Editors. 2011, Spon Press: London.

21. IESNA, IESNA Lighting Handbook, 9th ed. 2000, Illuminating Engineering Society of North America: New York.

22. Construction, P.s.R.o.C.M.o., Chinese Standard for daylight design of building, in GB/T 50033- 2001. 2001, China Building Industry Press: Beijing.

23. Moon, P. and D. Spencer, Illumination from a Nonuniform Sky. Illuminating Engineering, 1942. 37(10): p. 707-726.

24. USGBC. LEED-NC (leadership in energy and environmental design) version 3.0. 2006 [cited 2006; www.usgbc.org/LEED/].

25. BRE, BREEAM Hea 1:Visual comfort. 2014: London.

26. Ochoa, C.E., et al., Considerations on design optimization criteria for windows providing low energy consumption and high visual comfort. Applied Energy, 2012. 95: p. 238-245.

27. CIBSE, Guide A - Environmental Design. 2006, CIBSE Publications: London.

28. Wienold, J. and J. Christoffersen, Evaluation methods and development of a new glare prediction model for daylight environments with the use of CCD cameras. Energy and Buildings, 2006. 38(7): p. 743-757.

29. G. Ward and R. Shakespeare, Rendering with Radiance: The Art and Science of Lighting Visualization, Revised Edition. 2004: BookSurge, LLC.

30. Jacobs, A. Radiance Tutorial. 2012 [cited 2016.

31. McNeil, A., The Three-Phase Method for simulation Complex Fenestration with Radiance. 2014.

32. Andersen, M. and J. de Boer, Goniophotometry and assessment of bidirectional photometric properties of complex fenestration systems. Energy and Buildings, 2006. 38(7): p. 836-848.

33. Andersen, M., et al., Bi-directional transmission properties of Venetian blinds: experimental assessment compared to ray-tracing calculations. Solar Energy, 2005. 78(2): p. 187-198.

34. Andersen, M., M. Rubin, and J.-L. Scartezzini, Comparison between ray-tracing simulations and bi-directional transmission measurements on prismatic glazing. Solar Energy, 2003. 74(2): p. 157-173.

35. McNeil, A., et al., A validation of a ray-tracing tool used to generate bi-directional scattering distribution functions for complex fenestration systems. Solar Energy, 2013. 98: p. 404-414.

36. Reinhart, C.F. and M. Andersen, Development and validation of a Radiance model for a translucent panel. Energy and Buildings, 2006. 38(7): p. 890-904.

37. J, M., Validation of a lighting simulation program under real sky condtions. Lighting Research + Technology, 1995. 27(4): p. 181-188.

38. Mardaljevic, J., Validation of a lighting simulation program: a study using measured sky brightness distributions, Lux, , in The Eighth European Lighting Conference,. 1997: Amsterdam. p. 555-569.

39. Mardaljevic, J., Daylight design, simulation and compliance for solar building envelopes, in Energy Forum. 2013: Bressanone, Italy. 
